\title{
NASA Langley Research Center Systems Analysis \& Concepts Directorate Participation in the Exploration Systems Architecture Study
}

\author{
Jennifer Keyes ${ }^{1}$ and Patrick A. Troutman ${ }^{2}$ \\ NASA Langley Research Center, Hampton, Virginia, 23681, USA \\ Rudolph Saucillo, William M. Cirillo, Steve Cavanaugh ${ }^{3}$ \\ NASA Langley Research Center, Hampton, Virginia, 23681, USA \\ and \\ Chel Stromgren ${ }^{4}$ \\ Science Applications International Corp., McLean, VA 22102, USA
}

\section{Introduction}

The NASA Langley Research Center (LaRC) Systems Analysis \& Concepts Directorate (SACD) began studying human exploration missions beyond low Earth orbit (LEO) in the year 1999. This included participation in NASA's Decadal Planning Team (DPT), the NASA Exploration Team (NExT), Space Architect studies and Revolutionary Aerospace Systems Concepts (RASC) architecture studies that were used in formulating the new Vision for Space Exploration. In May of 2005, NASA initiated the Exploration Systems Architecture Study (ESAS). The primary outputs of the ESAS activity were concepts and functional requirements for the Crewed Exploration Vehicle (CEV), its supporting launch vehicle infrastructure and identification of supporting technology requirements and investments. An exploration systems analysis capability has evolved to support these functions in the past and continues to evolve to support anticipated future needs.

SACD had significant roles in supporting the ESAS study team. SACD personnel performed the liaison function between the ESAS team and the Shuttle/Station Configuration Options Team (S/SCOT), an agency-wide team charged with using the Space Shuttle to complete the International Space Station (ISS) by the end of Fiscal Year (FY) 2010. The most significant of the identified issues involved the ability of the Space Shuttle system to achieve the desired number of flights in the proposed time frame. SACD with support from the Kennedy Space Center performed analysis showing that, without significant investments in improving the shuttle processing flow, that there was almost no possibility of completing the 28-flight sequence by the end of 2010 .

SACD performed numerous Lunar Surface Access Module (LSAM) trades to define top level element requirements and establish architecture propellant needs. Configuration trades were conducted to determine the impact of varying degrees of segmentation of the living capabilities of the combined descent stage, ascent stage, and other elements.

The technology assessment process was developed and implemented by SACD as the ESAS architecture was refined. SACD implemented a rigorous and objective process which included (a) establishing architectural functional needs, (b) collection, synthesis and mapping of technology data, and (c) performing an objective decision analysis resulting in technology development investment recommendations. The investment recommendation provided budget, schedule, and center/program allocations to develop required

\footnotetext{
${ }^{1}$ Engineer, Systems Analysis \& Concepts Directorate, NASA LaRC/ MS 462.

${ }^{2}$ Engineer, Systems Analysis \& Concepts Directorate, NASA LaRC/ MS 462.

${ }^{3}$ Engineer, Systems Analysis \& Concepts Directorate, NASA LaRC/ MS 462.

${ }^{4}$ Senior Scientist at Science Applications International Corporation (SAIC). 1710 SAIC Drive, McLean, VA 22102.
} 
technologies for the exploration architecture, as well as the identification of other investment opportunities to maximize performance and flexibility while minimizing cost and risk.

A summary of the trades performed and methods utilized by SACD for the Exploration Systems Mission Directorate (ESAS) activity is presented along with how SACD is currently supporting the implementation of the Vision for Space Exploration.

\section{Exploration Systems Analysis}

The goals of exploration systems analysis are to formulate innovative and sustainable mission approaches, develop associated system and architecture concepts, and provide related technology requirements that will enable these missions to be implemented to meet ESMD program objectives. This includes assessments of "disruptive" technologies that could significantly alter exploration architecture implementations. Future scenarios are assessed from an integrated systems perspective to both define technology requirements and assess technology impacts. Quick response systems analysis in support of the ESMD will also need to be performed as required.

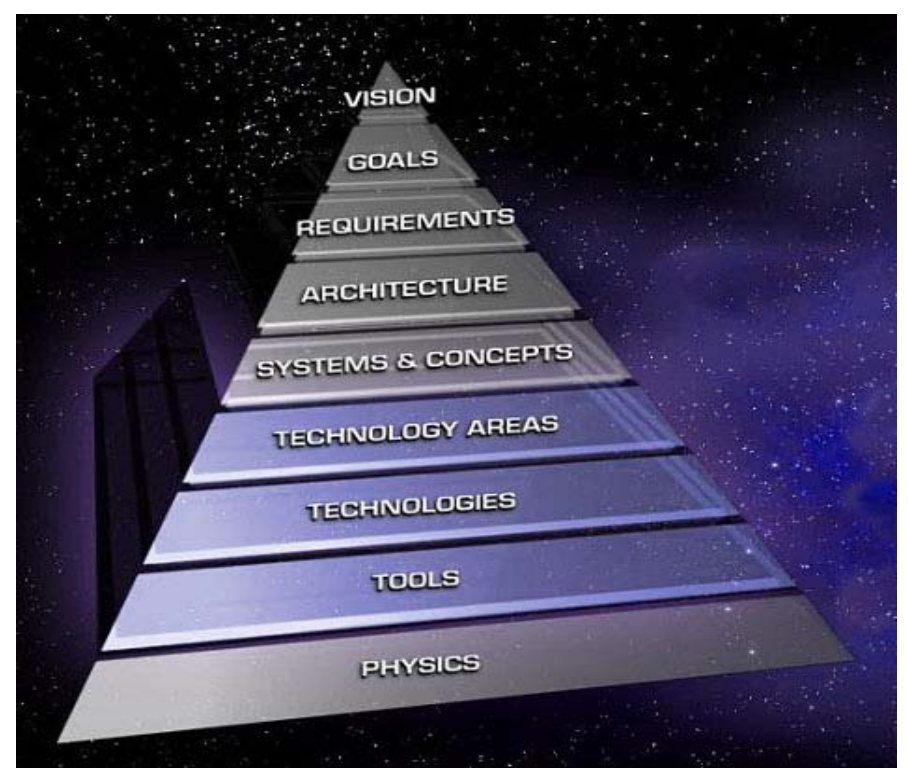

Figure 1. Elements of Exploration Systems Analysis.

Exploration systems analysis embodies a process composed of interrelated hierarchical elements that is extremely iterative in nature. A high level vision is needed to provide context from which to generate approaches for achieving derived goals and requirements. These "approaches" are generally thought of as architectures made up of various systems and concepts that embody distinct concepts of operations. Technology areas (sometimes referred to as "enabling capabilities" such as propulsion and structures) are identified to bound performance requirements. Individual technologies that support the technology areas are then assessed with respect to the desired performance requirements, readiness levels, and development cost. Results from the technology assessment are then used to guide investment strategies and to insert back into the architectures to assess projected technology performance as compared to the original technology area assumptions. Analytical tools that link the fundamental vision through the architectures, supporting systems, and technologies, down to basic physics, support the above analysis process.

\section{A. Vision}

"A vision is a cognitive image of the future which is positive enough to members so as to be motivating and elaborate enough to provide direction for future planning and goal setting." --Thomas/Greenberge 
In January of 2004, the President announced to the nation and the world his vision for NASA in the form of his Exploration Initiative. This strategic vision conveys a general philosophy to be followed now and in the future. Before this vision was established, NASA based its capability investment strategy upon a diverse set of future scenario studies that were performed independently of each other with inconsistent linkage to goals and requirements along with widely varying technology assumptions. No integrated view of the future could be established, and integrated costing was not possible -- yielding a "shopping list" of capabilities that were difficult to cost and prioritize.

\section{B. Goals and Requirements}

Well-established goals and requirements, along with a range of associated funding wedges and time periods, help focus the solution trade space. Systems analysis requires an integration function to formulate assumptions, establish metrics, normalize technology performance assumptions, ensure connectivity, and to facilitate cost and risk assessments. Agency-wide teams can then be created to develop architectures, advanced concepts, perform technology assessments and develop investment recommendations. An integration team manages, monitors, and coordinates the above activities to facilitate:

- Consistent and direct linkage to goals and requirements,

- Consistent technology assumptions,

- Integrated mission scenarios, and

- Integrated cost and risk assessments from the start of the process,

The net products are integrated architectures and enabling capabilities tied directly to the Vision for Space Exploration supported by investment priorities and associated budget profiles. Systems analysis is applied in the above context across a large mission space in support of the Vision for Space Exploration as depicted in Figure 2.

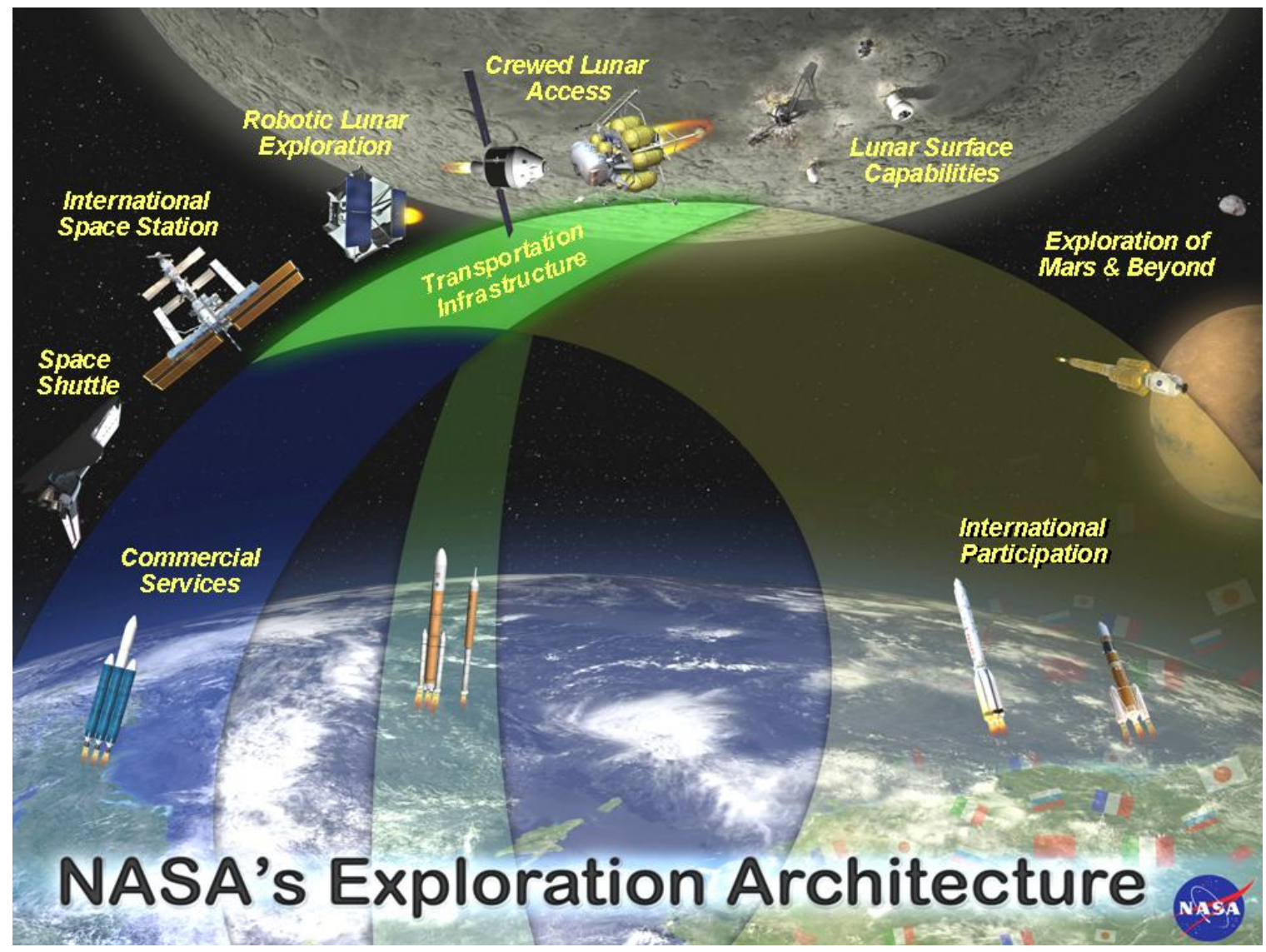

Figure 2. Missions in Support of the Vision for Space Exploration 


\section{Strategic Analysis}

Managing the development of large, complex systems from a strategic perspective presents a number of unique challenges. As the scope of systems become larger and more complex, as with the developmental exploration system, it becomes increasingly more difficult to integrate analysis at the system level. Complex systems, often referred to as "system of systems", are characterized by the fact that they are typically made up of a number of individual component systems, each of which has independent goals and can be discretely analyzed for performance, cost, and risk using detailed operational models.

Strategic management of these systems is difficult in that they are composed of a set of component systems that, while they operate independently, typically have multiple interdependencies that control the behavior of the global system. Because of these interdependencies, it is not possible to simply evaluate each component system separately and to then integrate the results. The global system must be evaluated as a whole in order to accurately predict behavior. However, it is typically not desirable, or even possible, to develop a single, holistic model of the global system. Such a model would be overly complex and would duplicate the capability of analysis models that already exist.

In fact, the goal of a strategic analysis capability is not to replace analysis at the component system level, but rather to provide a framework to integrate independent analysis of multiple system components. It is assumed that accurate models/descriptions/definitions of the individual systems exist at the component level. These models have the capability to independently evaluate the performance, cost, and risk of each component in a deterministic manner.

\section{Architectures and Advanced Concepts}

Architectures consist of the integrated set of functional building blocks that describe the method by which a set of activities are carried out to accomplish specified goals. The functional building blocks take the form of advanced systems concepts that are built upon technologies that are often referred to as enabling capabilities. Candidate mission architectures and system concepts will be modeled to allow systems analysis and trade studies. These studies will determine the effectiveness of the various system concepts in implementing the preferred system architectures and providing the desired functional capabilities. The key enabling capabilities required will be identified as a product of the trade studies, including desired performance levels. Analyses conducted will address not only performance, but cost, risk, and safety considerations.

\section{E. Technology Assessment}

One of the four goals outlined in The President's Vision for Space Exploration is to "develop the innovative technologies, knowledge, and infrastructures both to explore and to support decisions about the destinations for human exploration". This goal was strengthened by the findings of the "President's Commission on Implementation of United States Space Exploration Policy" headed by Pete Aldridge. One of the key findings of the Commission states that "the successful development of identified enabling technologies will be critical to the attainment of exploration objectives within reasonable schedules and affordable costs." In addition, one of the four major tasks of the recently completed Exploration Systems Architecture Study (ESAS) was to "identify key technologies required to enable and significantly enhance exploration systems and reprioritize near-term and far-term technology investments" using systems analysis. While the architecture and advanced concepts analysis refines architecture requirements, associated system concepts, and the related enabling capabilities; the technology assessment process connects the architectures to technology investment strategies through systems analysis.

The technology assessment process derives technology requirements from exploration architecture functional needs, develops and maintains a technology and mission database, and establishes a formalized approach for developing prioritized technology investment portfolios that are directly traceable to exploration architecture needs through systems analysis. The technology investment portfolios provide budget, schedule, and center/program allocations required to develop technologies for the exploration architecture. It identifies investment opportunities to maximize performance and flexibility while minimizing cost and risk.

\section{F. Analysis Environment}

A strategic systems analysis environment is required to enable distributed groups of participants to share information and solve problems in a consistent and managed way. Both local and remote users are 
able to upload and download data through common interfaces. Users can communicate and interact with each other in real time and they transfer data and analysis at whatever time is convenient for them. The environment captures the study process electronically in order to build databases to facilitate report generation and enhance design knowledge capture. A degree of device independence is necessary to maximize the ease at which remote users can be brought into the environment. Security of the environment must be maintained in order to protect sensitive or proprietary data. The assessments presented in this paper were developed in environments with the above characteristics although it must be noted at the current time that NASA has yet to implement such a capability across the agency.

\section{International Space Station (ISS) Assembly Sequence Assessment}

\section{A. Introduction}

The Vision for Space Exploration, announced in February 2004 by President George W. Bush, and NASA's resultant Level 0 Exploration Requirements provide several items of direction regarding the completion and operation of the International Space Station (ISS). In particular these documents provide direction that:

1. NASA shall complete assembly of the ISS, including US components that support US space exploration goals and components provided by foreign partner elements, planned for the end of this decade;

2. NASA shall retire the Space Shuttle as soon as assembly of the International Space Station is completed, planned for the end of this decade;

3. NASA shall focus US ISS research and technology on supporting exploration goals;

In addition, past direction has been given that all programs will be run in a manner consistent with safety concerns and the recommendations of the Columbia Accident Investigation Board (CAIB).

In response to these requirements the ISS and Space Transportation System (STS) program offices have developed a 28-flight shuttle sequence to complete station assembly, to provide partial resupply, and to support utilization. This sequence has a planned completion date of December 2010.

While the outlined flight sequence ostensibly meets the goals in the Exploration Vision and in the Level 0 requirements, there are a number of risks that have been identified that could impact the ability to complete the current plan. The most significant of the identified risks involved the ability of the STS system to achieve the desired number of flights in the proposed time frame.

Recent studies show that, without significant investments in improving the shuttle processing flow, that there is almost no possibility of completing the 28-flight sequence by the end of 2010. As shown in Figure 3 , there is at best an approximate 91\% probability of accomplishing 19 Total Space Shuttle flights by the end of FY2010. As additional issues are considered, such as a failure to Return to Flight (RTF) as scheduled, External Tank (ET) availability issues, and ground infrastructure transfer at Kennedy Space Center (KSC) to support future exploration needs, the likely number of flights that can be achieved by the end of FY2010 decreases as shown. 
Probability of Achieving 19 Flights by FY2010

(with Likely Case set of Core MAST assumptions)

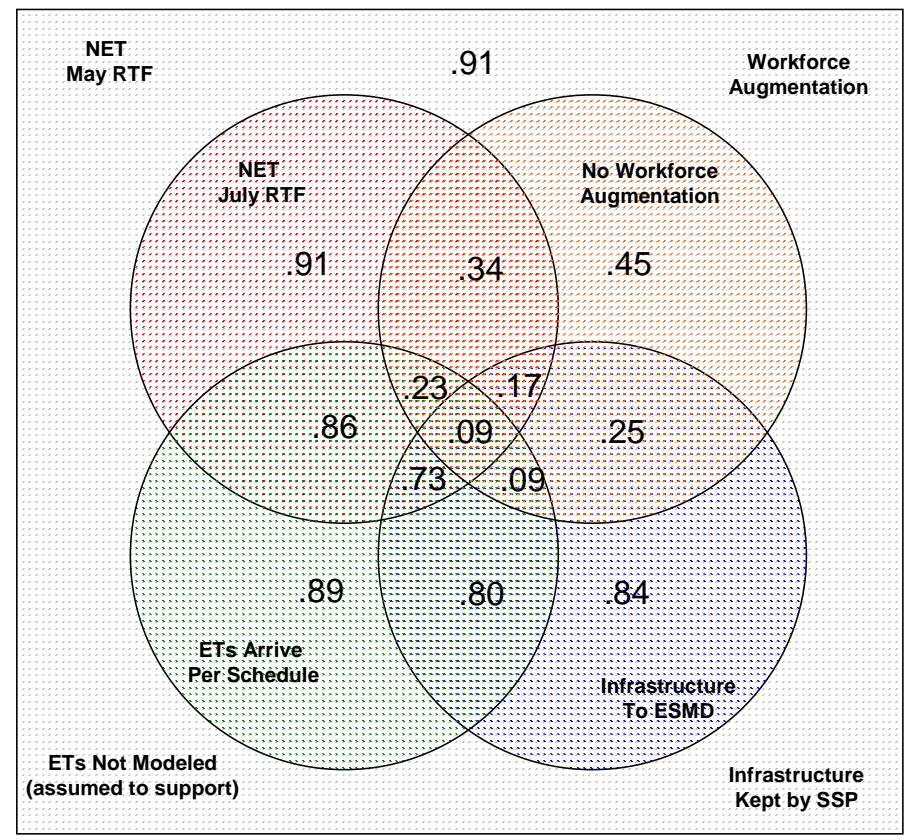

"Likely" Case

Figure 3. Probability of Achieving 19 Space Shuttle Flights by the End of FY 2010

The requirement to complete STS operations by the end of the decade is driven not only from a safety standpoint but also from a budgetary perspective. The current budget for exploration is predicated on the end of shuttle flights in 2010. Any extension of the shuttle retirement date would require either increased funding for NASA or a redirection of other funds within the agency, most likely those planned for exploration.

The primary goal of this study was to explore options for reducing the total number of Shuttle flights and reducing the number of elements in ISS assembly. In addition, the study evaluated transportation options to support ISS in the post-assembly period.

\title{
B. ISS-Transportation Analysis Model
}

In order to explore the potential trades between station configuration, shuttle flight sequence, CEV flights, and partner vehicle flights, a model, illustrated in Figure 4, was constructed to evaluate vehicle traffic, ISS requirements, and ISS operations. The synthesis model is comprised of three components:

- Transportation Module - A system model was constructed for ISS requirements and transportation. Based on an input shuttle flight sequence and other vehicle flight rates the model is able to calculate the ability of the transportation system to support station construction and resupply. The model specifically calculates mass and volume requirements in the following categories:

\author{
Crew Support \\ Pressurized Logistics \& Maintenance (L\&M) \\ Unpressurized L\&M Orbital Replacement Units (ORUs) \\ Pressurized Utilization \\ Unpressurized Utilization \\ Propellent
}

The model then loads these cargoes in a prioritized manner, accounting for accommodation factors and loading constraints, onto the available vehicles. The model accounts for changes in station altitude, storage capabilities, and flight timing constraints. A flight by flight accounting is kept of total delivered cargo (upmass and downmass) versus required values. 


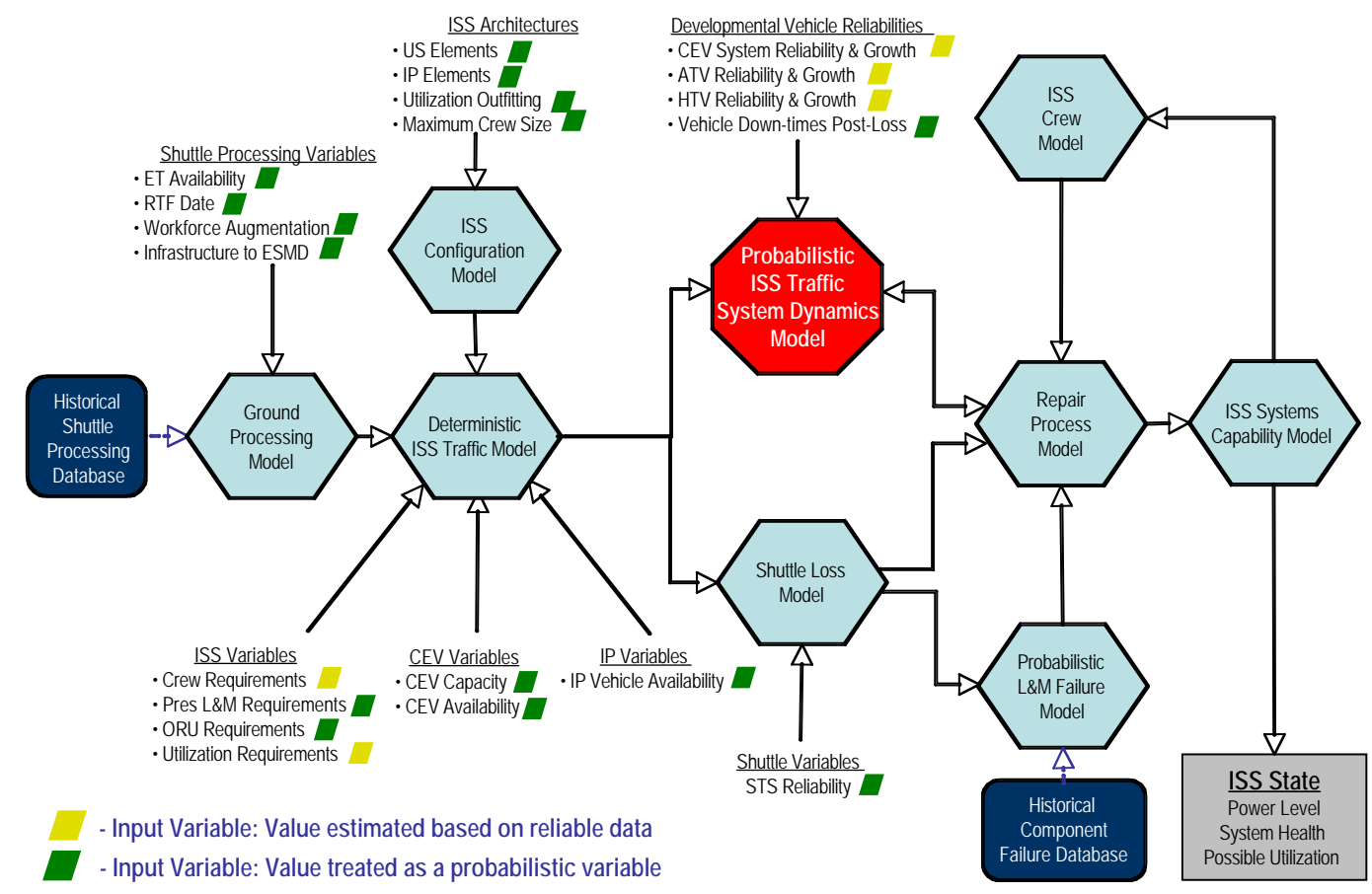

Figure 4. ISS-Transportation Analysis Model

The transportation module was directly adapted from the ISS Vehicle Integrated Performance, Environments, and Resources (VIPER) team's ISS traffic model VIPER Effectiveness and Optimization Model VENOM, the tool used by the ISS program to perform long-term ISS resupply planning.

Within the Transportation Module, achieved flight rates are input for all vehicles. Expected launch dates for the Shuttle were derived using the Manifest Analysis Simulation Tool (MAST). For each Shuttle flight sequence used, MAST was used to predict a "Likely Case" for expected launch dates, and a "Worst Case" for expected launch dates. These two cases were used in all analysis to bound the analysis.

- Crew Time Module - The crew time module calculates the availability of crew time for various functions, including utilization, based on maintenance requirements and the input traffic plan. This calculation is accomplished by first calculating the total crew hours available from station crew and visiting vehicle crews and then subtracting all fixed crew time requirements (including: EVA, maintenance, vehicle unloading, training, medical, etc.). The remaining hours are then available for utilization.

The crew time module is adapted from the VIPER team's VENOM model.

- Utilization Module - This module is used to determine if varying levels of desired utilization could be supported by a given traffic plan and station configuration. Within this module a given utilization goal is defined by: the number of International Standard Payload Racks (ISPR) required, the level of utilization resupply required, and the amount of crew time required. The utilization module compares these requirements to the station configuration including laboratory facilities, the permanent crew size, delivered ISPRs, and delivered resupply cargo, to determine if the utilization case can be completed. For this study, ESMD Case A utilization requirements were used for all analysis. This requirement set represents the utilization requirements to complete exploration research.

The model accounts only for Upmass, Downmass, Crew Hours, and ISPRs. There is no specific analysis of gravity loads (G-Loads) or late access. 


\section{Description of Analysis Completed}

This study dealt primarily with the alternative involving reduced numbers of Shuttle flights, scaled back ISS configurations, and alternate vehicle development.

As part of this analysis, three base Shuttle sequences and associated ISS configurations were initially evaluated (note-the number of Shuttle flights are always indicated with a " +1 " added, the additional flight indicates a potential Hubble repair mission which would add to the total number of shuttle flights):

\section{A. 11+1 Shuttle Flights - No additional ISS elements beyond current configuration}

B. 17+1 Shuttle Flights - Current configuration plus full truss, Node 2, Japanese Experiment Module (JEM) Experiment Logistics Module - Pressurized Segment (ELM-PS), JEM Pressurized Module (PM), JEM Exposed Facility (EF), and Columbus Orbital Facility (COF)

\section{22+1 Shuttle Flights - Current configuration plus full truss, Node 2, JEM ELM-PS, JEM PM, JEM EF, COF, and Node 3}

Within each case, the Shuttle sequence includes flights to assemble ISS, deliver outfitting, crew resupply, L\&M resupply, and ORU pre-positioning. Specific Shuttle flights within each sequence are described in the case results below. The amount of cargo delivered varies between cases based upon the capacities of each flight. Alternate vehicles were used to meet any gaps in requirements not met by Shuttle. In all cases the full upmass requirements are met.

Because of the desire to minimize any gap in U.S. manned spaceflight capability, all Shuttle sequences are conducted through FY2010. In cases where the sequence could likely be completed by an earlier date, the sequence is stretched so that the last flight will occur approximately at the end of FY2010. MAST analysis is used to predict likely launch dates for each sequence over this period.

For each ISS-STS run, two expected shuttle flight rate cases are used for analysis. The first, the "likely" case, represents the anticipated results if daylight launch restrictions are lifted after the two RTF flights. The second, the "Worst" case, represents the anticipated results if all current constraints on shuttle flight rate remain in place.

For each case, two sets of results are presented. The first chart shows the total required flight rates for all vehicles to support full ISS requirements. The second graph shows the total upmass requirement, including assembly mass, and the total upmass deliveries broken down by vehicle type. Because the upmass requirements, particularly for assembly, are driven by the shuttle schedule, the annual requirements can shift from case to case.

\section{Post-Assembly Traffic Strategies}

For each Shuttle/ISS case, two traffic strategies were evaluated:

1. Maximum CEV Case - Additional resupply and return requirements would bet met to the maximum extent possible through the use of CEV and CEV-derived vehicles. International Partners (IP) vehicles would be used only if already in the current plan (European Space Agency) ESA and JAXA supplied balance flights) or as required before CEV availability. The initial design used for CEV and CEV derivative vehicles is described in section 4 of this report.

2. Maximum IP Case - Additional resupply requirements would bet met to the maximum extent possible through the use of IP vehicles. CEV-derived vehicles would be used only to supply downmass capability not available through IP flights.

In both strategies, CEVs are used for USOS crew rotation. Soyuz are used to provide USOS crew rotation prior to CEV availability.

\section{E. Summary of Baseline Cases}

Table 1 summarizes the flight rate data for all of the baseline cases. 
The results of the baseline case indicate that there are difficulties with both the $17+1$ and the $22+1$ assembly sequences. The $17+1$ sequence completes assembly and resupply but provides pre-positioning for only a very small number of ORUs. The lack of ORU pre-positioning not only increases post-assembly delivery requirements but also significantly increases the risk of ISS failure in the time period between shuttle retirement and CEV-unpressurized availability.

\begin{tabular}{|c|c|c|c|c|c|c|c|}
\hline & $\begin{array}{c}\text { 11+1 } \\
\text { CEV MAX } \\
\text { Likely }\end{array}$ & $\begin{array}{c}\mathbf{1 7 + 1} \\
\text { CEV MAX } \\
\text { Likely }\end{array}$ & $\begin{array}{c}\text { 17+1 } \\
\text { CEV MAX } \\
\text { Worst }\end{array}$ & $\begin{array}{c}22+1 \\
\text { CEV MAX } \\
\text { Likely }\end{array}$ & $\begin{array}{c}\mathbf{1 7 + 1} \\
\text { I P MAX } \\
\text { Likely }\end{array}$ & $\begin{array}{c}\text { 17+1 } \\
\text { I P MAX } \\
\text { Worst }\end{array}$ & $\begin{array}{c}22+1 \\
\text { I P MAX } \\
\text { Likely }\end{array}$ \\
\hline Space Shuttle & $11+1$ & $17+1$ & $17+1$ & $22+1$ & $17+1$ & $17+1$ & $22+1$ \\
\hline ATV & 0 & 10 & 10 & 10 & 10 & 10 & 10 \\
\hline ATV (US Purchased) & 0 & 0 & 0 & 0 & 0 & 0 & 0 \\
\hline HTV & 0 & 8 & 8 & 8 & 8 & 8 & 8 \\
\hline HTV (US Purchased) & 0 & 0 & 0 & 0 & 22 & 22 & 12 \\
\hline Soyuz (US Purchased) & 5 & 9 & 9 & 9 & 9 & 9 & 9 \\
\hline Progress (US Purchased) & 5 & 15 & 16 & 10 & 11 & 12 & 13 \\
\hline CEV-Crew & 6 & 11 & 11 & 11 & 11 & 11 & 11 \\
\hline CEV-Pressurized Cargo & 12 & 15 & 15 & 16 & 5 & 5 & 5 \\
\hline CEV-Unpressurized Cargo & 2 & 5 & 5 & 4 & 0 & 0 & 0 \\
\hline HLLV & 0 & 0 & 0 & 0 & 0 & 0 & 0 \\
\hline TOTAL USOS Flights & $41+1$ & $90+1$ & $91+1$ & $90+1$ & $93+1$ & $94+1$ & $90+1$ \\
\hline
\end{tabular}

Ariane Transfer Vehicle (ATV), H-II Tranfer Vehicle (HTV), Heavy Lift Launch Vehicle (HLLV)

\section{Table 1: Summary of Baseline Case Flight Rates}

The $22+1$ sequence provides adequate ORU pre-positioning. However, there is some possibility that 23 flights could not be completed by the end of FY2010. The MAST results indicate that using the likely case assumption, 23 flights could only just be accommodated. Any deviation from those assumptions would reduce the number of available flights.

\section{F. Additional Analysis}

The results of the base cases showed that with $17+1$ Shuttle flights, a large number of unpressurized logistics flights were required in the post-assembly period to deliver the required number of ORUs. In addition, there is some likelihood that certain critical ORUs could fail before they could be delivered by alternate vehicles. For both these reasons, it is desirable that a significant number of ORUs be prepositioned using the Shuttle.

Thus, an additional case was developed that added two additional unpressurized logistics flights to the $17+1$ flight sequence case. These two additional flights would deliver a substantial number of additional ORUs, reducing post-assembly requirements and reducing risk of ORU failure.

Table 2 shows the flight sequence and launch dates used for the 19+1 Space Shuttle flight sequence. 


\begin{tabular}{|c|l|c|c|}
\hline$\#$ & \multicolumn{1}{|c|}{ Flight } & Likely & Worst \\
\hline 1 & LF1 - RTF1 & 2005 & 2005 \\
\hline 2 & ULF1.1 - RTF2 & 2006 & 2006 \\
\hline 3 & 12A - P3/P4 & 2006 & 2006 \\
\hline 4 & 12A.1 - P5/Pres Logistics & 2006 & 2007 \\
\hline 5 & $13 A-$ S3/S4 & 2007 & 2007 \\
\hline 6 & $13 A .1-$ S5/Pres Logistics & 2007 & 2007 \\
\hline 7 & $15 A-$ S6 & 2007 & 2007 \\
\hline 8 & $10 A-$ Node 2 & 2007 & 2008 \\
\hline 9 & ULF2 - Outfitting & 2007 & 2008 \\
\hline 10 & 1E-COF & 2008 & 2008 \\
\hline+1 & Hubble Servicing Mission & 2008 & 2008 \\
\hline 11 & 1J/A - ELM-PS/SPDM & 2008 & 2008 \\
\hline 12 & 1J - JEM PM & 2008 & 2009 \\
\hline 13 & 17A - Outfitting/Logistics & 2008 & 2009 \\
\hline 14 & ULF5 - Rails/Unpres Logistics & 2009 & 2009 \\
\hline 15 & 19A - 6-Crew Capacity & 2009 & 2010 \\
\hline 16 & ULF6 - Unpres Logistics & 2009 & 2010 \\
\hline 17 & 2J/A - JEM EF/Rails & 2010 & 2010 \\
\hline 18 & Unpres Logistics & 2010 & 2010 \\
\hline 19 & Unpres Logistics & 2010 & 2010 \\
\hline
\end{tabular}

Table 2: 19+1 Flight Shuttle Sequence

\section{G. Conclusions}

The current 28-flight sequence is unlikely to be completed by the end of 2010. The extension of shuttle program beyond that date would result in a major impact to the budget available for exploration and, in turn, the completion of exploration requirements themselves.

Aside from procurement of alternate transportation and greatly accelerating Shuttle processing, the only methods to gain any assurance of Shuttle retirement in the 2010 timeframe is to eliminate flights from the proposed sequence, either through reduction in delivery of utilization and ORUs or by removing elements from ISS assembly.

There are reduced final ISS configurations that meet commitments to ESA and JAXA and have the potential to reduce the number of planned flights required by up to 11 flights. These configurations have only a small impact on the total potential utilization that could be completed on-board the ISS.

\section{Lunar Lander Concept Definition Activities within the NASA LaRC Systems Analysis and Concepts Directorate}

The NASA Langley Systems Analysis and Concepts Directorate (SACD) has extensive experience in the conceptual design and analyses of lunar surface elements. In the summer of 2005, SACD was a lead participant in the NASA Headquarters-sponsored Exploration Systems Architecture Study (ESAS). The purpose of this study was to establish a viable lunar architecture concept and implementation plan supporting the Vision for Space Exploration. One SACD responsibility supporting ESAS was the development of innovative lunar lander concepts which provided valuable information for the selection of a reference lunar architecture. More recently, in the spring and summer of 2006, SACD was a lead organization participating in the Constellation Advanced Projects Office-sponsored Lunar Lander Preparatory Study. The purpose of this study was to extend the ESAS lunar lander analysis by assessing a wider range of lunar lander concepts considering updated requirements and specific trades and analyses. 


\section{A. ESAS Lunar Lander Studies}

LaRC SACD provided analyses of a range of "non-traditional” lunar lander concepts to support ESAS lunar architecture definition (Figure 5). For example, single-stage lander concepts with either pressure-fed or pump-fed engines were developed and evaluated vs. 2-stage, pressure-fed reference concepts. Configuration trades included number and size of engines. SACD also evaluated concepts which used the Crew Exploration Vehicle (CEV) as the habitable element of the lunar lander. For these "CEV-to-thesurface" concepts, configurations included the CEV Crew Module plus lunar lander ascent and descent propulsive stages. The range of SACD lunar lander analyses performed for ESAS included: concept definition, vehicle and system sizing, vehicle packaging, center-of-gravity analysis, engine gimbal analysis, Earth Departure Stage (EDS) and launch vehicle performance analysis, payload direct return capability analysis, and delta- $\mathrm{V}$ analysis as a function of thrust-to-weight.

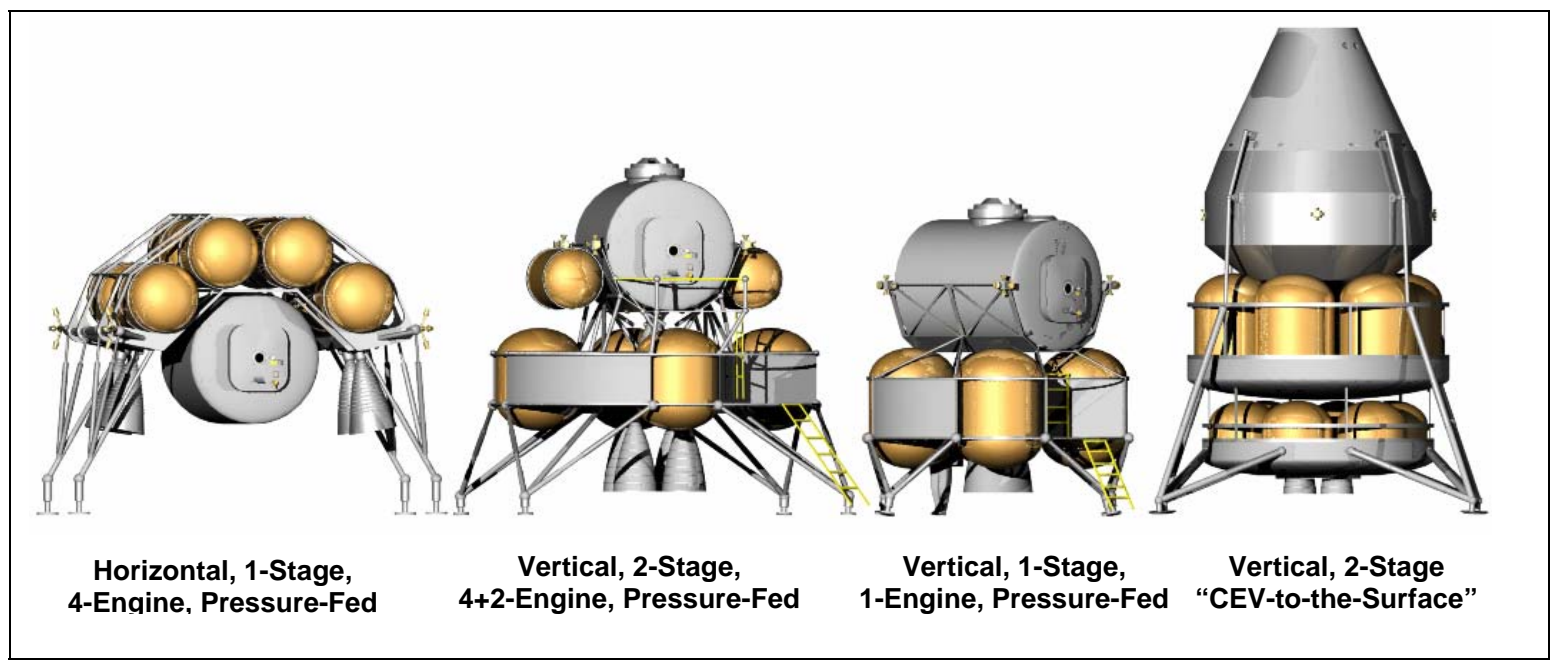

Figure 5. Examples of LaRC SACD-defined lunar lander concepts supporting ESAS architecture definition.

\section{B. Lunar Lander Preparatory Study Concepts}

The reference lunar architecture defined as a product of the ESAS activity is being further refined as the specific goals, needs and objectives of the Vision for Space Exploration are established. Objectives for lunar surface activities are also in the process of being developed by the Lunar Architecture Team (LAT), an Agency-wide team managed by the NASA Exploration Systems Mission Directorate (ESMD). Once the lunar surface strategic objectives are defined, they will be used as the basis for future exploration system studies that will, over the next several years, lead to the establishment of lunar exploration system requirements that will be used for detailed system definition.

During the spring and summer of 2006, in parallel with the LAT lunar surface strategic objectives activity, several internal ESMD lunar exploration studies were performed to prepare for the receipt of the approved lunar surface objectives. An example of these studies, the Lunar Lander Preparatory Study (LLPS) was formulated to "pick up" where the ESAS team left off and incorporated programmatic directions received since the conclusion of the ESAS activity. Results from the LLPS will position the Constellation Program to be responsive to the lunar surface strategic objectives when provided by the LAT.

The objective of the LLPS was to define innovative lunar lander approaches that meet a fixed requirement set and fall within specific bounding cases for trade studies. Each NASA Center-based lunar lander design team used common requirements and trade space boundaries to perform analyses and concept definition of innovative lunar lander designs.

\section{Phase 1 Concepts}

Phase 1 of the study explored multiple design concepts, including the relationship of the lander to potential surface systems. Products included refined descent stage propulsion system and payload 
packaging options; refined ascent stage concepts including crew cabin layout, minimum volume options and propulsion system packaging; lander structural analysis; and launch vehicle packaging.

LaRC SACD focused on lunar lander-level and lunar architecture-level trades during Phase 1 of the LLPS. Emphasis was placed on assessing architecture "closure" with respect to launch vehicle and Earth Departure Stage (EDS) performance. Also, LaRC SACD lunar lander design concepts were developed to enhance lunar surface operations for both sortie and outpost missions. This included establishing lander configurations that facilitate crew egress/ingress and cargo unloading/deployment.

The LaRC SACD study methodology was based on establishing upper-bound and lower-bound examples of lunar lander concepts based on system mass and performance. Within these bounds, key trade parameters were defined and lunar architecture-level and lunar lander element-level trade studies were performed. Figure 6 illustrates the range of lander concepts developed by LaRC SACD during Phase 1 of the LLPS.

With a mass estimate of $46.6 \mathrm{t}$, the Revised ESAS Lunar Lander is the LaRC SACD upper-bound example of a lunar lander concept. Updates from the ESAS lander concept include:

- Sized for a 95-day low-Earth orbit loiter period prior to trans-lunar injection (vs. a 25-day period assumed during ESAS). This new requirement increases lander size since it significantly impacts the quantity of cryogenic propellant (LOX and LH2) which will boil off without active thermal control

- Sized for smaller CEV based on revised CEV design analysis. This decreases lander size due to a lower lunar orbit insertion (LOI) propellant requirement (i.e., the lunar lander performs the LOI maneuver and "pushes" the CEV into lunar orbit; a smaller CEV results in a lower lander propellant requirement for this maneuver sequence)

- Ascent stage engine geometry was revised based on the Service Module engine

- Ascent stage propellant changed from LOX/CH4 to storable

The 2-Stage, Split Habitat Lander is the LaRC SACD concept most similar to the revised ESAS Lunar Lander. Total mass for the sortie-mission configuration is $42 \mathrm{t}$. Mass savings vs. the revised ESAS Lander Lander is achieved by staging the pressurized element. That is, the pressurized element is divided into a minimum volume ascent stage habitat and a larger volume surface habitat. The ascent stage separates from the descent stage and surface habitat prior to lunar ascent resulting in an ascent stage requiring significantly less propellant than the revised ESAS Lunar Lander. Mass reduction is also achieved through the use of a nested, toroidal descent stage propellant tank.

The Descent-Assisted Split Habitat (DASH) Lander is a $43.8 \mathrm{t}$ concept which is reconfigurable to accommodate a dual habitat or cargo mission supporting a lunar outpost. This concept also includes a split habitat which reduces overall system mass and facilitates egress/ingress and cargo unloading/deployment. A key feature of the DASH lander is the use of a retro module to perform the lunar orbit insertion (LOI) maneuver and most of the descent to the lunar surface. At approximately $2 \mathrm{~km}$ altitude, this retro module is staged and the DASH lander module completes the propulsive descent profile. Another principal feature of the DASH lander is the use of an external "suitport" concept for EVA that eliminates the need for an airlock and mitigates lunar dust/habitable volume contamination issues.

The Hybrid Global Lander (HGL) is a "lower bound" concept which was defined to explore a revised "minimum" mission concept for lunar exploration. For this lander concept, the HGL Crew Lander with minimal pressurized volume supports 2-crew, 7-day "mini-sortie" missions; the Crew Lander and a separate Habitat Lander support 4-crew, 28-day "super-sortie" missions. A Cargo Lander configuration has also been defined based on the HGL Descent Stage. Key features of the HGL concept include: global landing capability for mini-sortie missions, common elements used across the three lander configurations,, and landers leave behind re-useable assets for follow-on missions to the same location. A operations concept change vs. the ESAS reference concept is the use of the Earth Departure Stage (EDS) to perform the lunar orbit insertion (LOI) maneuver sequence instead of the lunar lander.

The Unpressurized Crew Transport lander is another example of a "lower bound" lander concept. This concept is a two-stage lander which incorporates dockable, rear-entry space suits on an unpressurized ascent stage. The dockable, rear-entry EVA suits mitigate lunar dust/pressurized volume contamination issues and potentially provide enhanced crew safety and contingency options since the crew are in pressure suits during ascent and descent. For this concept, the EDS also performs the LOI maneuver sequence.

The Horizontal, 1-Stage Lander is a concept which is optimized for lunar surface operations. The horizontal design facilitates crew egress/ingress and cargo unloading/deployment (i.e., minimizes travel 
distance to the lunar surface). Additionally, analysis performed jointly with the Jet Propulsion Laboratory demonstrated that this lander configuration is uniquely suited for the deployment of a $10 \mathrm{t}$ surface fission power system proposed for a permanently crewed lunar outpost. An additional benefit of the horizontal lander configuration is that the LOX/CH4 propellant tank location provides inherent radiation protection during in-space transit and on the lunar surface. Similar to several other lander concepts, the EDS performs the LOI maneuver sequence for this lander concept.

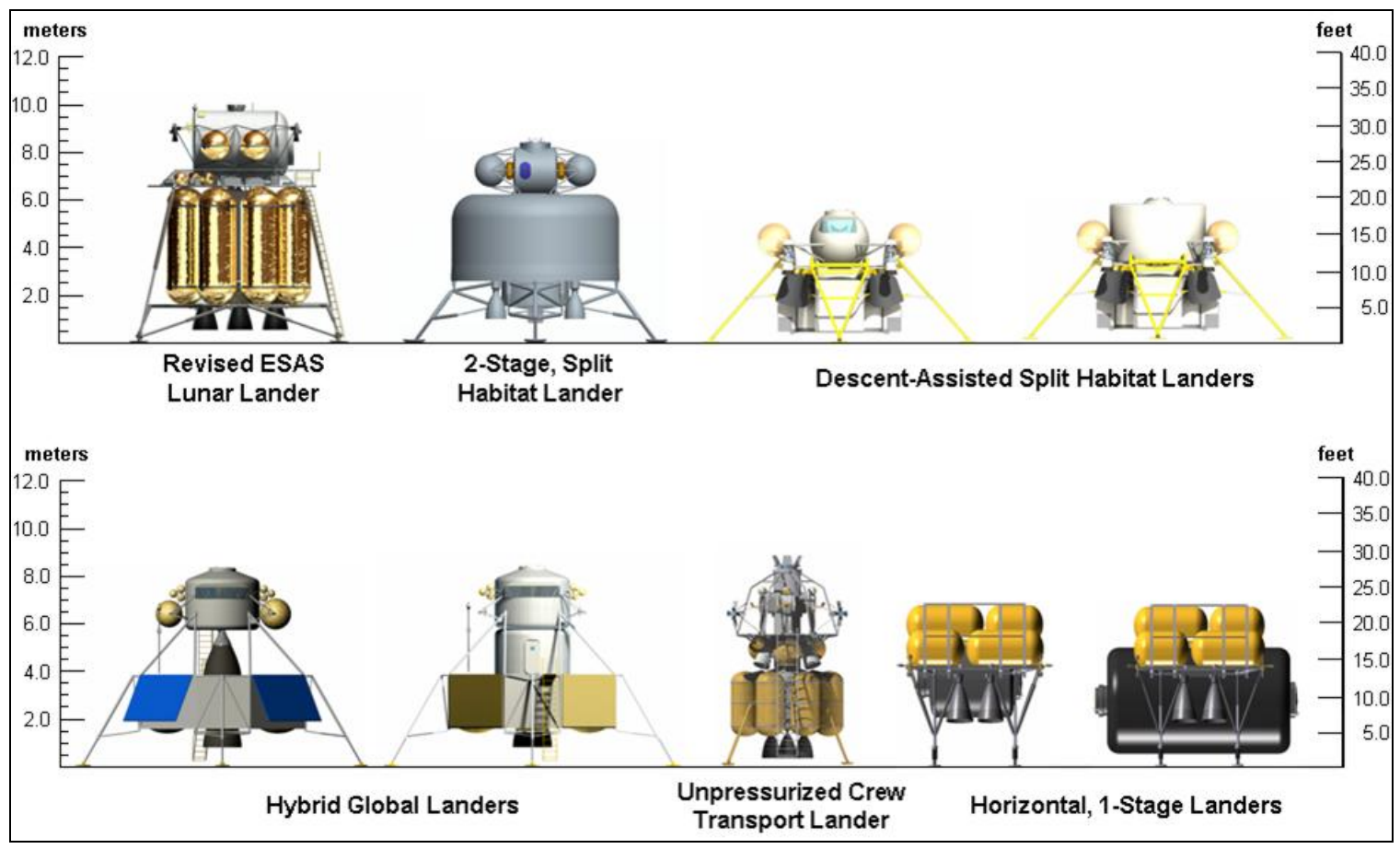

Figure 6. LaRC SACD lunar lander concepts developed for the Lunar Lander Preparatory Study, Phase 1.

\section{Phase 2 Concepts}

Phase 2 of the study was based on downselected concepts from Phase 1. In this phase, performance estimates and design concepts were refined. Additionally, cost and risk analyses were performed using Constellation-sanctioned methods. Each lander team was given specific guidance and direction regarding Phase 2 concepts and products.

LaRC SACD was directed to continue analyses of the DASH lander and horizontal lander concepts. Specific guidance for DASH analyses was to: improve analysis of trajectory and aborts, further develop concepts for deploying astronauts (alternatives to suitports); further refine drop stage operations, trajectories, altitude and velocity at staging; and further develop the small ascent/transport habitat stage. Guidance for horizontal lander analyses included: integrate horizontal lander concepts using all multicenter team members who contributed horizontal concepts; fully develop horizontal lander concepts including launch and landing; and investigate payload unloading options. A description of the DASH and horizontal lander configuration revisions in Phase 2 is provided below.

The Phase 2 DASH concept is illustrated in Figure 7. Configuration changes from the Phase 1 DASH concept include:

- Changed Surface Habitat diameter from $4 \mathrm{~m}$ to $3 \mathrm{~m}$ to improve crew visibility during final descent

- Baselined two side-located habitable volumes utilizing inflatable structures technology. These habitable volumes are $6 \mathrm{~m}^{3}$ each and can be configured as an airlock or crew sleep area

- $\quad$ Changed the Transport Habitat configuration from spherical to gem-shaped

- Improved definition of structural attachments of propulsion subsystem and habitats

- Adopted a modular lander gear approach with updated landing gear attachment points (a fixed gear concept is baselined) 
- Adopted a two engine main propulsion system configuration (single engine on each side). These are Shuttle orbital maneuvering engine (OME)-based engines which are required to be throttleable

- $\quad$ Upgraded RCS thrusters to $100 \mathrm{lbf}$

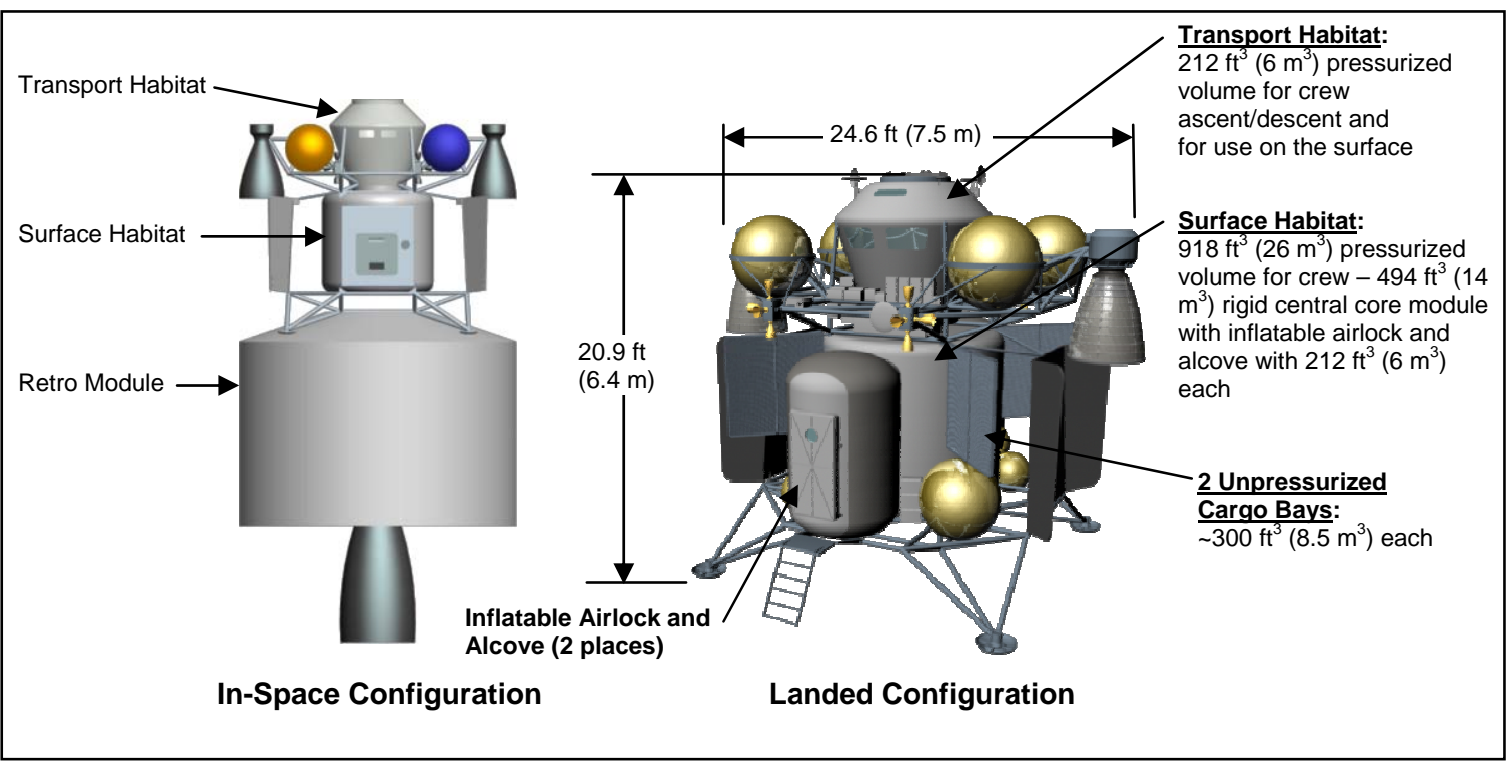

Figure 7. The Descent-Assisted Split Habitat (DASH) lander sortie mission configuration.

For the deployment and maintenance of a permanently crewed outpost (assumed as the follow-on step of lunar exploration beyond the 7-day lunar sortie missions), the DASH lander concept is reconfigurable to support autonomous, uncrewed delivery of outpost infrastructure (e.g., an outpost surface habitat, pressurized rovers, power systems, etc.) as well as resupply logistics (crew resupply, science hardware, spares/maintenance, and gas/water). Figure 8 illustrates a DASH lander configured for the autonomous delivery of a $>100 \mathrm{~m}^{3}$ outpost surface habitat designed to support a crew of 4 for 6 month missions.

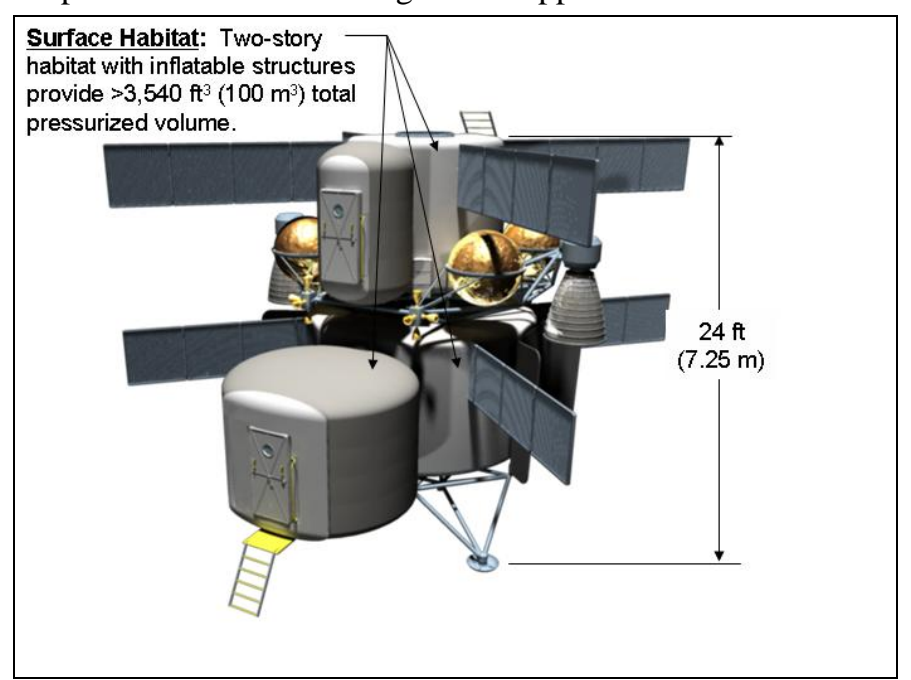

Figure 8. The Descent-Assisted Split Habitat (DASH) lander Outpost habitat configuration.

As per direction from the Phase 1 review panel, LaRC SACD led a multi-Center team to integrate and refine horizontal lander concepts developed during Phase 1. A Quality Functional Deployment (QFD) selection process was used to downselect to a single horizontal lander concept. Using this process, team members from LaRC, MSFC, and KSC provided revisions to their Phase 1 concepts, agreed upon evaluation criteria, and ranked concepts based on the evaluation criteria to arrive at a single concept agreed to by consensus. Several evaluation criteria weightings were examined which emphasized lander 
performance supporting an outpost-class mission. For these weightings, concepts which provide large cargo carrying capability and which facilitated cargo deployment received high scores. Figure 9 illustrates the horizontal lander concept developed based on this multi-Center synthesis of concepts. This downselected concept has been designated "Cargo Star" (C-Star).

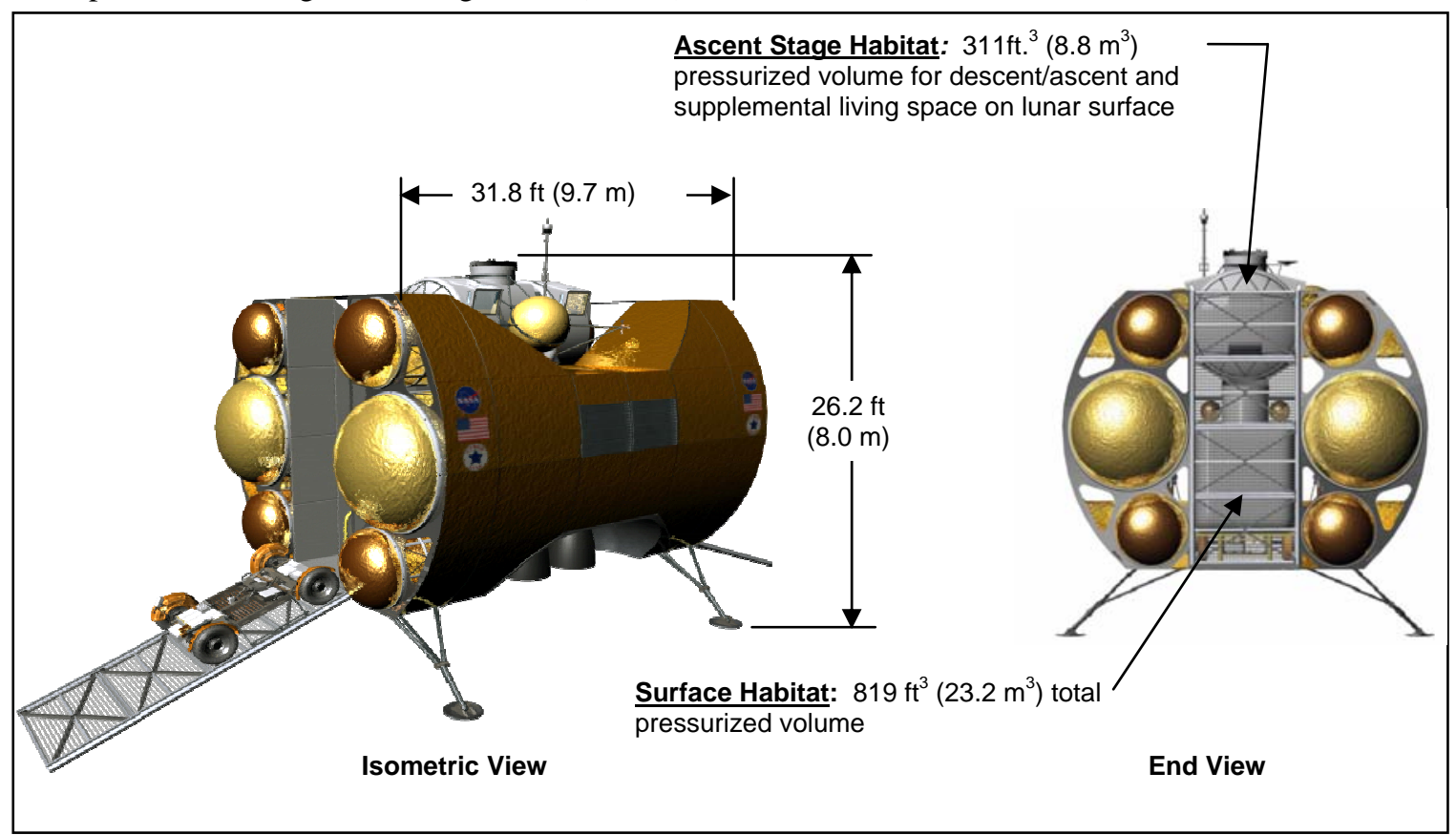

Figure 9. The Cargo Star (C-Star) lander sortie mission configuration.

A key feature of the C-Star lander concept is facilitation of lunar surface operations including crew egress/ingress and deployment of large cargo. For outpost missions this includes the automated delivery of infrastructure elements such as the outpost surface habitat. Figure 10 illustrates the C-Star lander configured to deliver a $100 \mathrm{~m}^{3}$ outpost surface habitat.

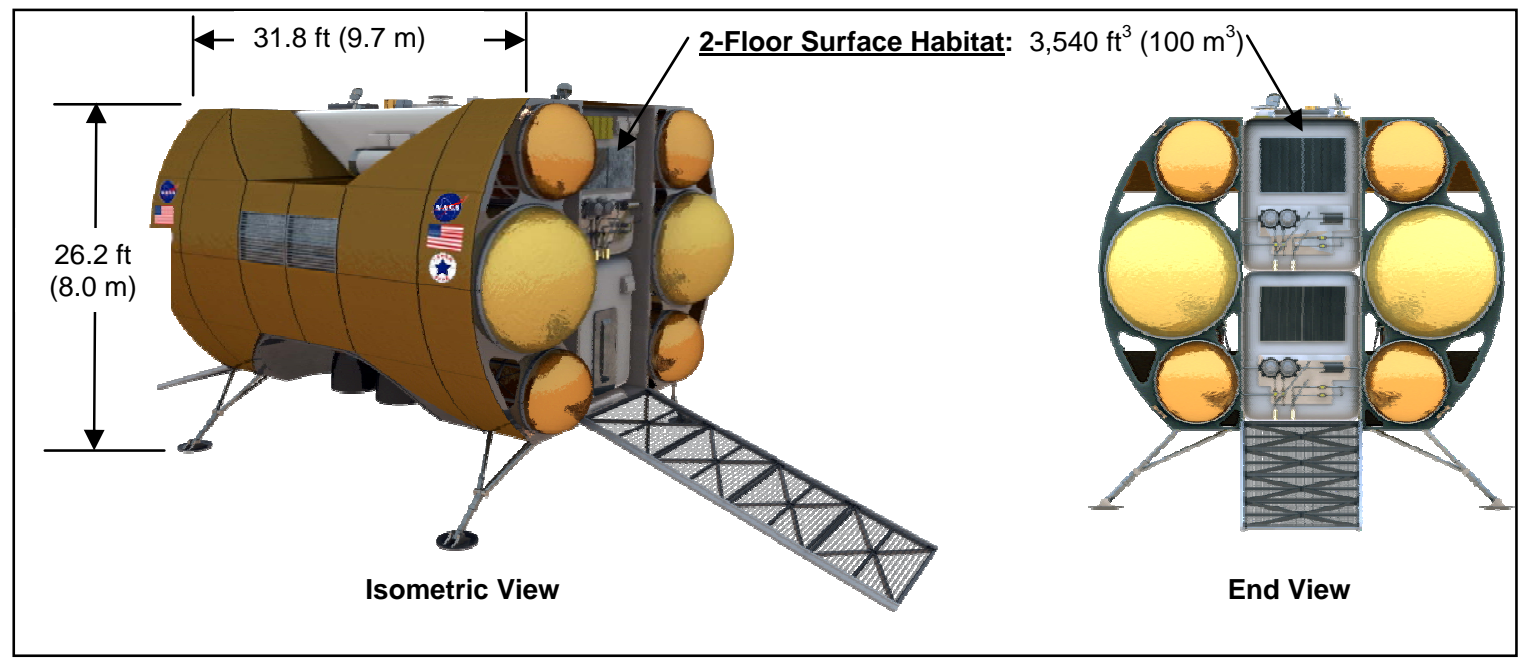

Figure 10. The Cargo Star (C-Star) lander Outpost habitat configuration. 


\section{Technology Assessment for ESAS}

The technology assessment for the ESAS activity resulted in a revised Exploration Systems Mission Directorate (ESMD) technology investment plan that is traceable to the ESAS architecture. To develop this investment plan, a rigorous and objective process was implemented which included (a) establishing architectural functional needs, (b) collecting, synthesizing and mapping of technology data, and (c) performing an objective decision analysis resulting in technology development investment recommendations. The investment recommendation provides budget, schedule, and center/program allocation to develop required technologies for the exploration architecture, as well as the identification of other investment opportunities to maximize performance and flexibility while minimizing cost and risk. Several of the primary ground rules were: 1 ) the recommended plan must fit within the President's NASA's FY 2006 Exploration Systems Mission Directorates budget submission to Congress, 2) all of the technology development activities must be mapped to architecture needs, and 3) the Technology Readiness Level (TRL) for each project must achieve a TRL 6 by the Preliminary Design Review of the first system for which it will be incorporated.

The ESAS Technology Assessment staff consisted of an implementation team and expert assessment panel. The implementation team was responsible for assembling functional needs based on the ESAS architecture, assembling technology data sheets for technology project(s) that met these needs, and provides an initial prioritization of each technology project's contribution to meeting a functional need. The expert assessment panel examined the functional needs and technology data sheets for missing items, performed the final prioritization, and assessed the figures of merit (FOMs) for each need at the architecture level. All results were then entered into a technology investment calculator for the decision makers use in formulating a technology portfolio.

\section{A. Technology Assessment Process}

The overall Technology Assessment Process is illustrated in Figures 11 through 13. The process is divided into three distinct steps 1 ) define the architecture functional needs and technology options to meet the requirements, 2) assess the criticality of the functional needs and the technology options, 3) prioritize the technology options to meet the architecture functional needs.

The first step (Figure 11) defined the architecture and its functional needs. Architectural trade studies were being conducted to support the Exploration Systems Architecture Study (ESAS) for four different mission sets: near-term Space Station support, initial lunar short-time sorties, longer-term lunar outpost, and far-term Mars missions. The architectural elements (launch and in-space transportation, habitats, space suits, etc.) were defined based on mission requirements. For each element, the functional needs such as structure, propulsion, power, etc. were defined. State-of-the-art and advanced technology options were assessed by the architecture team and were used as a point of departure for the Technology Assessment Team. The architecture operational mode and elements, functional needs and technology options will continue to be refined until a complete architecture is defined that meets the Level 0 mission requirements for the mandated budget constraints.

The functional needs for the architecture were assessed for completeness and iterated as the architecture changed because these activities were conducted in parallel. (Note: the functional needs will be updated to functional requirements later in the development cycle). In addition, the criticality of the functional needs as measured by the Space Exploration Figures of Merit (Safety, Affordability, Risk, Extensibility, and Performance) was assessed. For example, structure has a larger impact on overall performance than an Integrated System Health Management (ISHM) system, however, the ISHM has a larger impact on safety than structure.

Technology options were identified and mapped to the functional needs. The technology options consisted of those identified by the architecture development team, current technology development programs and other possible technology solutions. The architectural elements, functional needs, and technology options were put into a knowledge repository for assessment and prioritization. 


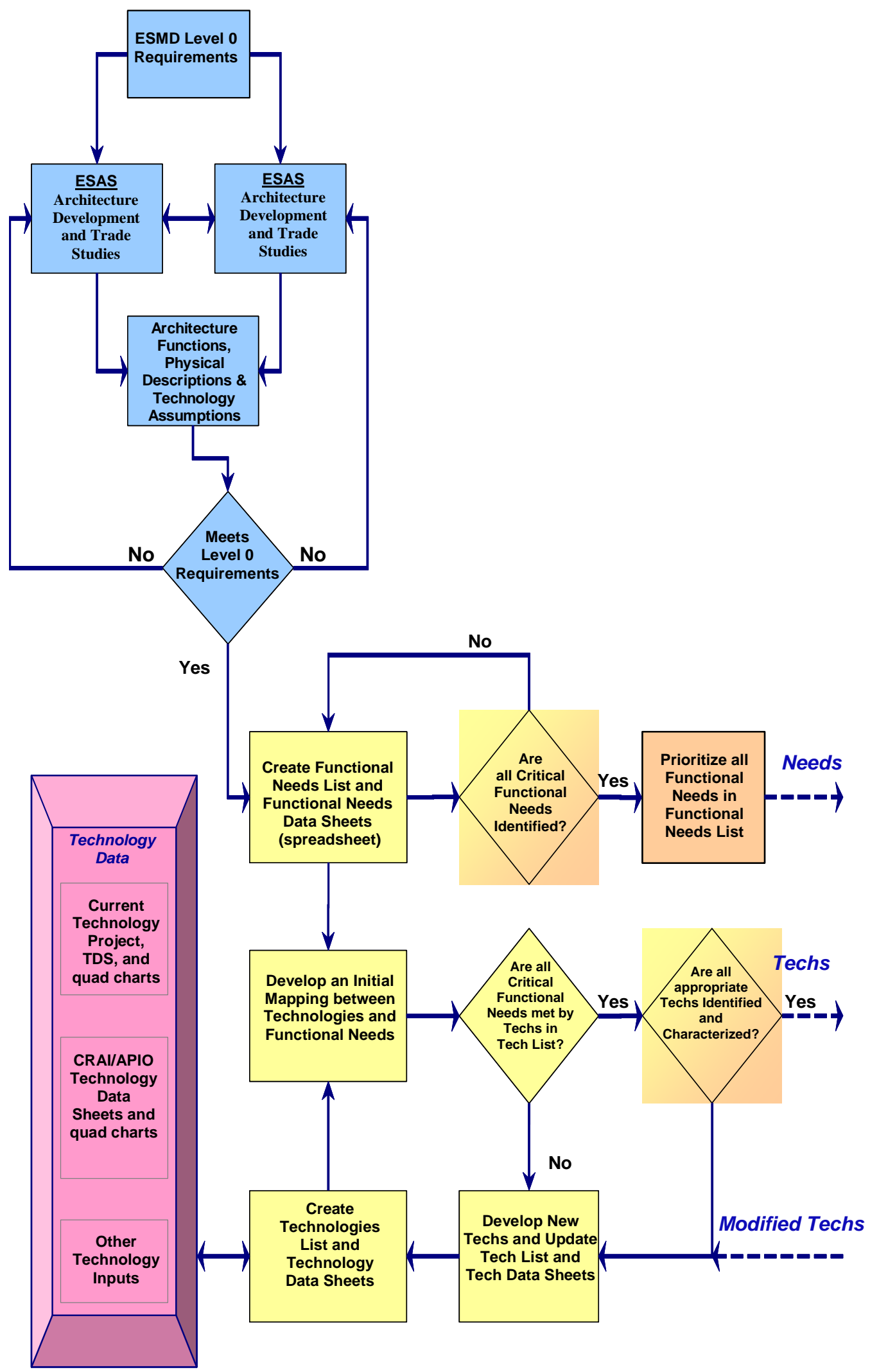

Figure 11. Technology Assessment Process Architecture Definition, Functional Needs, and Technology Options 
The second step in the technology assessment process (Figure 12) was to assess the technology options that may meet each of the mission/element/functional needs. Initially, the technologies were assessed as needed, desired, or not applicable. The architecture team defined the technology needs by either specifying state-of-the-art or a required new technology. If a technology met or exceeded the new technology requirement, it was designated a "must have" technology (later called a "gotta have" technology). If a technology option exceeded a state-of-the-art specified technology, it was designated as a desired or "wanna have" technology. If a technology option has the potential to be incorporated into the assessment process but needed to be modified or grouped with other technologies to meet a functional need, these technologies were further defined by the Implementation Team. If a technology only met a state-of-the-art specified technology, it was dropped from consideration. Also, each functional need was assessed to determine if at least one technology option exists to satisfy the need.

The technology options were then sorted by "wanna have" and "gotta have" and could be manipulated by changing the weights on the program Figures of Merit.

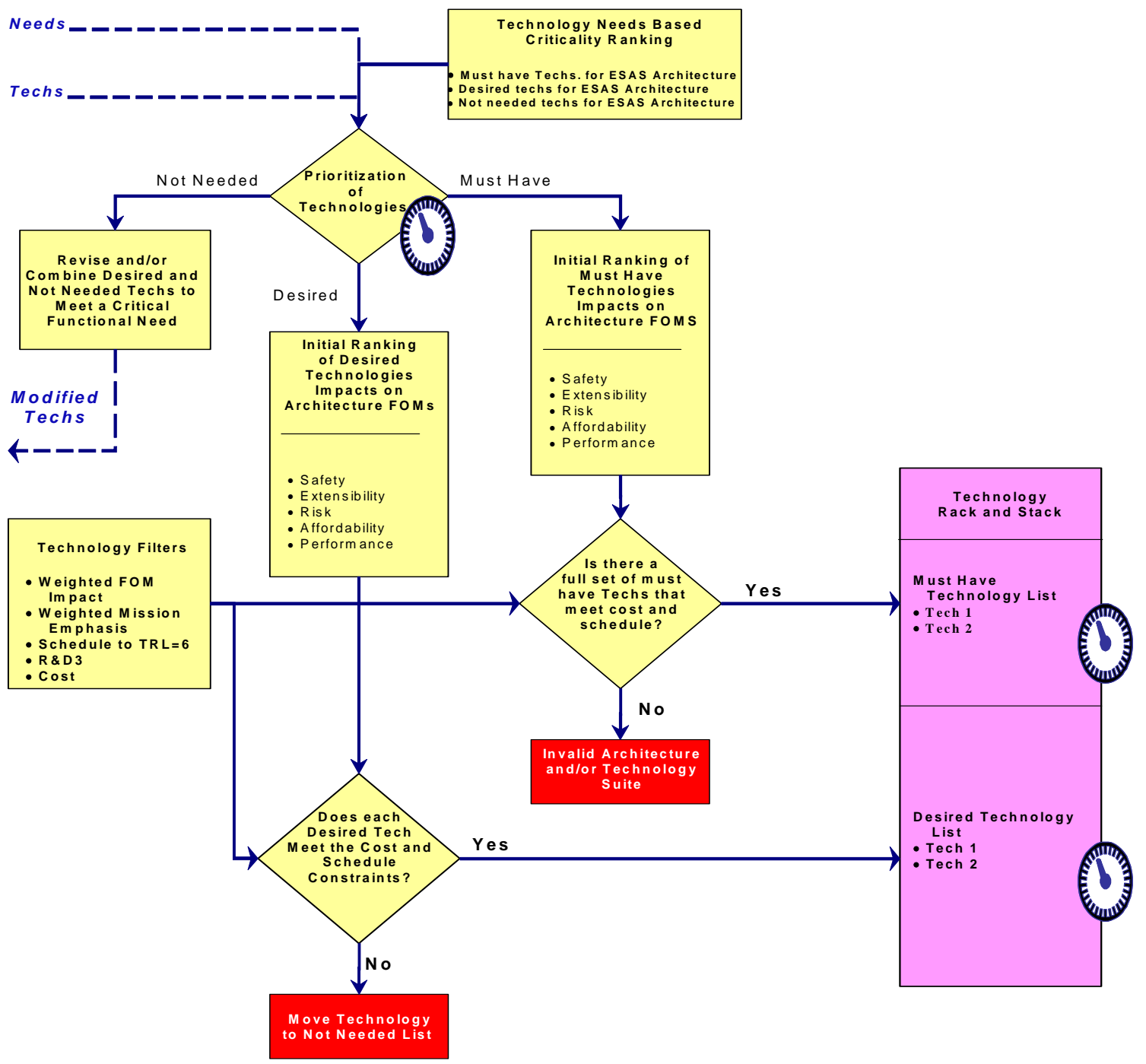

Figure 12. Technology Assessment - Functional Needs and Technology Options Assessments 
The third step (Figure 13) was to prioritize the technology options based on the program FOM impact, mission impact, element impact, functional need impact, ability of technology to meet or exceed the functional need, "Gotta Have" or "Wanna Have", technology development budget, and technology development schedule meeting need dates, and technology development risk. A technology calculator was developed to adjust the weights for each of the impacts and to determine technology development cost needs and schedule impacts. Deliverables of the technology assessment were a prioritized list of technologies, technology development risk, schedule, cost, and yearly funding profiles.

In order to do the Technology Assessment process a Management Team, an Implementation Team, and Expert Assessment Panel were formed. The Implementation Team interfaced with the ESAS Architecture Team to develop the functional needs and technology selections (either state of the art or advanced), developed the technology option data and maps to the functional needs/elements/missions, and the technology calculator. The Expert Panel assessed the criticality of the functional needs and the impact of the technology options to the functional needs and solicited additional technology options if required. The ESAS Technology Assessment team at headquarters conducted the final technology prioritization and developed the recommendations for the Space Exploration program.

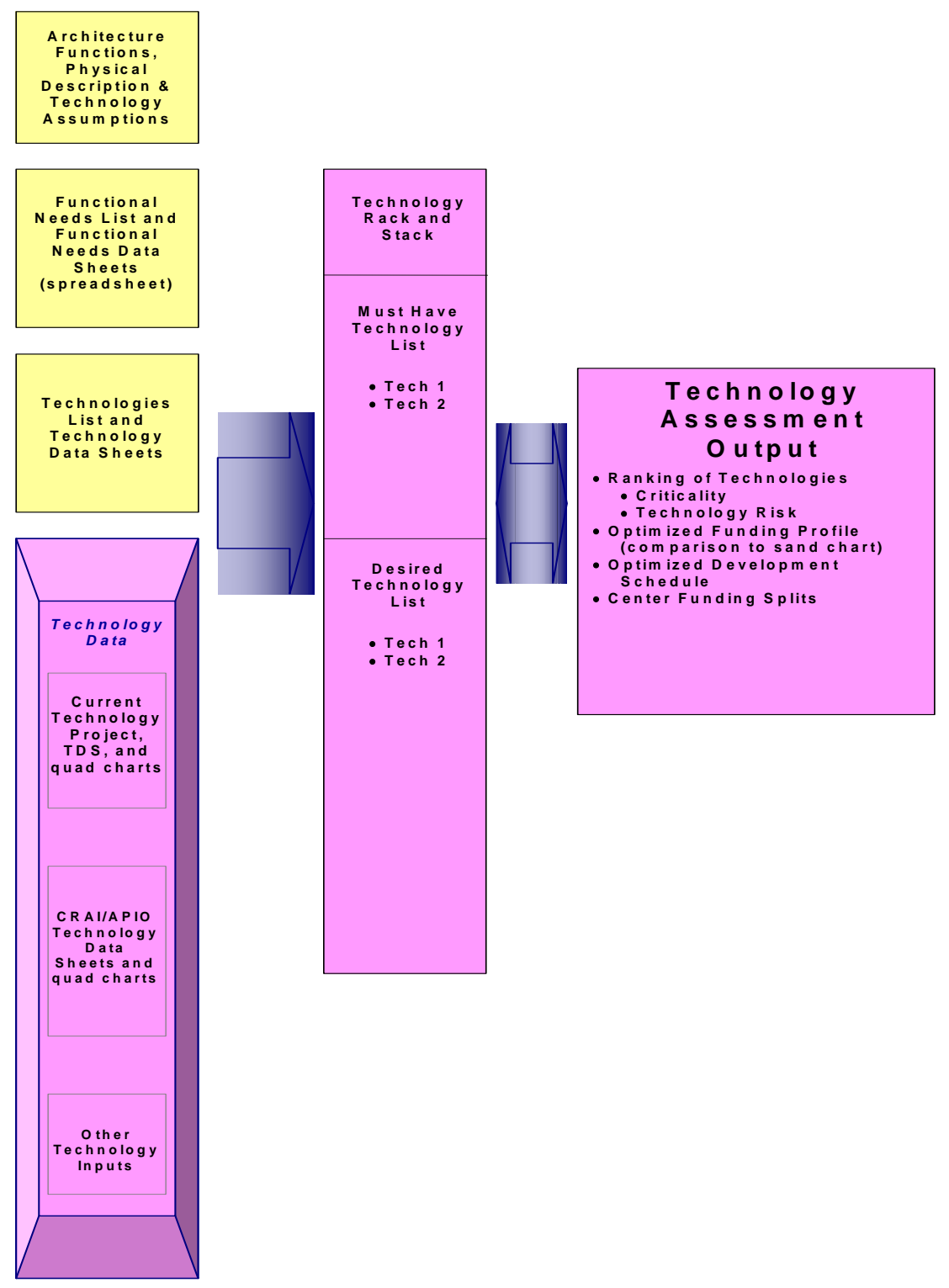

Figure 13. Technology Assessment Process - Technology Option Prioritization 


\section{B. Figures of Merit}

For the technology selection prioritization process, each of the technology needs and technology options were evaluated on their impact to the Exploration Systems Architecture Study (ESAS) Figures of Merit (FOMs) shown in Figure 14. To simplify the technology assessment process, the technology impacts on the FOMs were ranked at the FOM category level: Safety and Mission Success, Extensibility/Flexibility, Programmatic Risk, Affordability, and Performance.

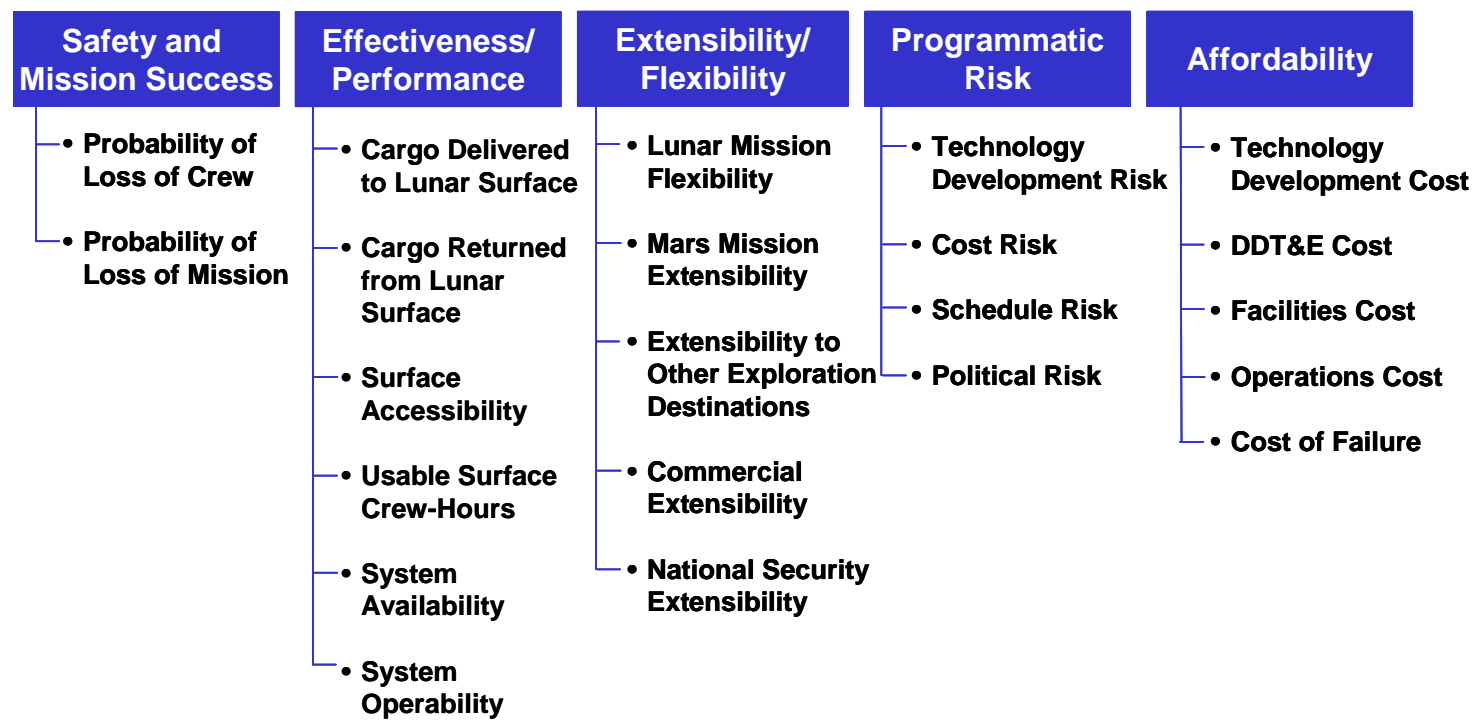

Figure 14. ESAS Figures of Merit

\section{Functional Breakdown Structure \\ 1. FBS Definition Process}

In order to capture and organize technology options applicable to exploration systems, elements of exploration architectures were decomposed into functional groupings according to a Functional Breakdown Structure (FBS). Several FBSs were utilized to capture the breadth of technologies related to major hardware elements and associated infrastructures. These individual FBSs were derived by Technology Assessment Team members using their own expertise and previously developed breakdown structures.

Each FBS consists of a table in Excel with rows used for functional groupings and columns used for information capture. Information is categorized by: Performance Challenges and Requirements; Assumed Technology; Technology Need Date; Rationale/Benefits of Assumed Technology; Data Source; Current State-of-the-Art; and Potential Issues/Risks. In most cases functional groupings within each FBS go multiple levels deep to allow sufficient technical detail to support technology assessments.

\section{Mission Classifications}

In order to better understand technology needs as a function of time, the Exploration Vision was divided into several missions representing different time phases. The mission classifications are ISS, Lunar Sortie, Lunar Outpost, and Mars. The ISS Mission performs the crew and logistics transfer functions required to support ISS once the Shuttle has been retired. The Lunar Sortie Mission performs the initial crewed flights to the Moon for brief stay times of several days. The Lunar Outpost Mission establishes a long duration (months) human presence on the Moon's surface and presumably builds on the capabilities established by the Lunar Sortie Mission. The Mars Mission establishes initial capabilities for landing humans on the Martian surface and is assumed to occur after operations are established for the Lunar Outpost Mission. 
For each of these missions a separate Excel workbook was used to organize the various mission-specific architectural elements. Individual sheets of the workbook contain the FBS table specific to a particular element of the architecture.

\section{Individual FBS Types}

There were five FBS types developed for the technology assessment activity. They are General Element, Systems Engineering, Communications Infrastructure, Operations, and In-Situ Resource Utilization. The following sections describe each of these FBS types.

\section{Functional Needs}

\section{Process for Establishing Functional Needs}

Establishing the functional needs of the Exploration Systems Architecture Study (ESAS) architecture was accomplished using a three-step process, which included:

- Review of the architecture requirements and related assumptions

- Identification of system level requirements

- Definition of critical challenges and technologies

Due to incomplete definition of the ESAS architecture in the early stages of the study, an initial set of functional needs was derived from the "Point of Departure" architecture developed by Johnson Space Center (JSC). As the ESAS architecture matured, the needs were modified to reflect the current state of the ESAS architecture.

\section{Functional Needs}

Functional needs of the ESAS architecture were mapped by the NASA Langley Research Center (LaRC) Technology Assessment team to the Functional Breakdown Structure (FBS) described above by: defining the performance challenges and requirements of the ESAS architecture, determining the assumed technologies and associated rationale/benefits, and identifying additional applicable technologies (Table 3).

\section{Table 3. FBS with Functional Need Definition Columns}

\begin{tabular}{|c|c|c|c|c|c|c|c|c|c|c|c|c|c|}
\hline \multicolumn{3}{|c|}{ ELEMENT: Crew Exploration Veh } & \multirow[b]{2}{*}{\begin{tabular}{|c|}
$\begin{array}{c}\text { Need } \\
\text { Date } \\
\text { (TRL =6) }\end{array}$ \\
\end{tabular}} & \multirow[b]{2}{*}{$\begin{array}{c}\text { Assumed } \\
\text { Technology } \\
\text { (\#) = Current TRL }\end{array}$} & \multirow[b]{2}{*}{$\begin{array}{l}\text { Rationale/Benefits } \\
\text { for Assumed Technology }\end{array}$} & \multirow[b]{2}{*}{ Source } & \multirow[b]{2}{*}{$\begin{array}{c}\text { Current } \\
\text { SOA }\end{array}$} & \multirow[b]{2}{*}{$\begin{array}{l}\text { Potential } \\
\text { Issues/ Risks }\end{array}$} & \multicolumn{5}{|c|}{ Applicable Technologies } \\
\hline & $\begin{array}{l}\text { Iement Functional Breakdown } \\
\text { Structure (FBS) }\end{array}$ & $\begin{array}{l}\text { Performance } \\
\text { Challenges and } \\
\text { Requirements }\end{array}$ & & & & & & & $\begin{array}{c}\text { Tech. } \\
1\end{array}$ & $\begin{array}{c}\text { Tech. } \\
2\end{array}$ & $\begin{array}{c}\text { Tech. } \\
\mathbf{3}\end{array}$ & $\begin{array}{c}\text { Tech. } \\
4\end{array}$ & Tech. 5 \\
\hline \multicolumn{14}{|c|}{1.0 Structure } \\
\hline \multirow{3}{*}{$\begin{array}{l}2.0 \\
3.0 \\
4.0 \\
5.0\end{array}$} & Protection & & & & & & & & & & & & \\
\hline & $\begin{array}{l}\text { Propulsion } \\
\text { Power }\end{array}$ & & & & & & & & & & & & \\
\hline & Thermal Control & & & & & & & & & & & & \\
\hline 6.0 & Avionics \& Software & & & & & & & & & & & & \\
\hline 7.0 & Environmental Control and Lif & ipport & & & & & & & & & & & \\
\hline 8.0 & Crew Support and Accommod & & & & & & & & & & & & \\
\hline 9.0 & Mechanization & & & & & & & & & & & & \\
\hline
\end{tabular}

A set of performance challenges and requirements was defined for each element of the ESAS architecture by mapping top-down system requirements to the FBS elements. Associated technology technical performance measures were defined where possible for each of the requirements to aid in the translation of the system and subsystem level requirements into technology requirements. In the case where no requirement or challenge was identified within an FBS element for a particular architecture element, "None Identified” was noted.

The next step in the process was to document the technology assumptions of the ESAS architecture. The baseline technologies that were assumed for the architecture were identified as well as the associated Technology Readiness Levels (TRLs). The technologies were classified as either "state-of-the-art" (SOA) or a critical technology development need, based on the defined TRL. The associated rationale/benefits were also documented along with the reference source of the information, current SOA, and potential issues/risks.

The final step in the process was a bottoms-up technology identification assessment. Inventories of applicable technologies - additional technologies that were not included in the initial baseline assumptions, 
were developed for each FBS element. From this inventory, those technologies that met the need date and addressed critical challenges were listed as Applicable Technologies on the FBS. Technical data sheets (TDSs) were developed for each of the applicable technologies (see section 7.0 for a description of the TDSs). A team of subject matter experts reviewed the TDSs and also identified additional applicable technologies, and generated corresponding TDSs.

Delineation was established between the state-of-the-art (SOA) technologies, requiring minimal to no development, and critical technology needs, which require significant development for successful application to the architecture. Based on the defined TRL and need date, assumed technologies with a TRL of 6 or higher were classified as SOA, while those with a TRL lower than 6 were defined as a critical technology development need. As with the performance requirements definition, the technology assumptions for a Point Of Departure (POD) architecture were used initially, and were augmented as the ESAS architecture and technology assumptions matured.

\section{Gotta Haves and Wanna Haves}

After the functional needs were defined, the technologies that apply to them were known throughout the analysis as "gotta have" or "wanna have". A "gotta have" was a technology that addresses a critical functional need. Critical functional needs were defined as areas where technology development is required to fulfill the architecture requirements. A "wanna have" was a technology development that would enable the architecture to go beyond the stated need. For example, if in a certain area the current state of the art was identified by the architecture team as sufficient for the needs of the architecture, then it was not a "gotta have" area. However, a technology, that if developed, would enhance this area in terms of one or more of the five figures of merit, mission success / safety, affordability, programmatic risk, extensibility, and technical performance, it would be submitted to the process and considered as a "wanna have".

\section{EAP Management Matrix and FBS Needs}

The Expert Assessment Panel (EAP) Management Matrix included a combination of critical needs that had been approved by the ESAS Core Team and needs submitted by the EAP and agreed to be critical by a majority vote of the EAP members. These needs were categorized by each of the level one FBS areas. The other dimension of the EAP Matrix was the overall criticality and five Figures of Merit (FOMs) for each of the architectures, ISS, Lunar Sortie, and Lunar Outpost. The EAP members voted on the rankings to fill in this matrix, which was later translated back to the original FBS and input into the Space Calculator (SC) to impact the final analysis and technology development prioritization.

There were both advantages and disadvantages to carrying multiple sets of needs and matrices throughout the assessment process. One distinct benefit, of starting the EAP Management list of needs in addition to the full FBS list with needs listed per element and per architecture, was that the EAP needs list greatly reduced the complexity, and therefore the number, of needs to be considered by the EAP and ESAS leadership. There were several disadvantages as well, however, all that stemmed from the full FBS and needs list being developed and implemented first and then the EAP Management list being created and maintained by a separate group within the assessment process. Extra time was required to map the EAP needs back to the appropriate individual FBS areas, as well as elements within each of the architectures, as applicable based on the relevant architectures determined by the EAP voting. This was necessary, as the EAP needs were not captured with element contexts. This lack of element context caused each of the needs versus FOM rankings to be considered the same for every element the need was mapped to for the SC. Although the EAP matrix was representative in general, having remained with only the full FBS for each element and each architecture would have allowed for further delineation between elements.

\section{E. Technology Options to Meet Functional Needs}

\section{Overall Solicitation Process}

The solicitation of data on the many technologies under development within the agency began with assigning members of the implementation team, along with points of contact (POCs) located at NASA Langley Research Center, to each of the level two functional breakdown structure (FBS) areas. Emphasis was placed on getting data to satisfy critical functional needs where technology development was known to be needed to enable the Exploration Systems Analysis Study (ESAS) Architecture. However, inputs of technologies that would enhance the architecture beyond the strict need specified were strongly encouraged. Once all the data was collected from this group the Expert Assessment Panel (EAP) was given 
the opportunity to review what had been gathered and submit any additional information they felt was missing to directly address either a critical or non-critical functional need.

\section{Technology Data Sheets}

The Technology Data Sheet (TDS) was developed with the specific information needed by the Space Calculator (SC). An example data sheet can be seen in Figure 15. There were three categories of data included in the TDS, vital, enhancing, and supporting, based on how the information impacted the analysis process within the SC.

The vital pieces of information were the Technology Project Name, Architectures Impacted by Technology, Current TRL, Target Year for TRL=6, Total Cost for TRL $=6$ (millions), Research Degree of Difficulty, and Duration to TRL 6. The Technology Project Name, is the title of the technology being documented. The Architectures Impacted by Technology is seen on the TDS as a row of buttons that each say "yes" or "no". The responses captured, when these indicators are clicked, form the start of the mapping process that occurs with all TDSs to identify their architecture and element applicability. The remaining pieces of vital information are all included in the Technology Maturation section of the TDS. The current TRL is input as a value of a single digit from 1 to 9 based on the standard NASA TRL scale, included as Appendix A2. The target year for TRL $=6$ is the four digit year in which the technology is expected to reach TRL 6 status. The total cost is the amount, in millions of dollars, that this development of the technology from where it is currently in TRL to a TRL of 6. The Research Degree of Difficulty, commonly referred to as $\mathrm{RD} 3$ or $\mathrm{RD}^{3}$, is an indication of how likely the technology development will be to reach its milestones. RD3 is input as a single digit ranging from 1 to 5 , and detailed definitions of these levels are included in Appendix A3. Duration to TRL 6 is simply the number of years of development expected to be required to mature the technology from its current TRL to a TRL of 6.

The enhancing areas of the TDS add important details to those collected in the vital areas. The Percentage Cost by Center, or center splits, is the percentage of the total technology development funding that will go directly from NASA Headquarters to that center regardless of where the funding may go from the center, such as to industry or academia. These percentages must overall add up to $100 \%$ and are entered as just the numerical value of the percentage without the \% symbol, e.g. 100 not $100 \%$. The other enhancing area is the Technology Development Schedule. This is a list of the major milestones along the development path, what year they will occur in, the TRL the milestone will mark the technology reaching, and the cost, in millions of dollars, for that milestone to be reached. This is considered enhancing as it adds granularity to the overall cost associated with the development and enables a cost profile to be built as opposed to assumed based only on the overall total cost.

The remainder of the data collected on the TDS is supportive of the decision making process. The Contact Information section of the TDS captures the name, phone numbers, center affiliation, and email address for both the primary and secondary POCs for the technology development documented in the TDS. This is used to contact the most knowledgeable person if there are any questions during the assessment process. The Technology Description allows someone not familiar with the particular technology development submitted to make a more informed decision. The Technical Performance Measures and Dependence on Other Technologies to Meet Capability Expectations areas of the TDS as well as the Figures of Merit Impacts and Rationales all add further details to the knowledge available and confidence in the vital and enhancing information submitted in other sections, so the development being described may be properly assessed. The Technical Performance Measures, TPMs, list the metrics to gauge the technology's development against. The current state of the art and the projected value for this metric are recorded as well as a probability, entered as a percentage, that the projected value can be achieved by the proposed development. Without these values it is difficult to ascertain how much benefit a technology will have on the architecture if developed. The Dependence on Other Technologies to Meet Capability Expectations is important as it allows leaders to consider suites or groups of technologies that should be developed and assessed together to have an architecture functional need completely met. The Figures of Merit Impact Ratings and Rationales provide insight as to not only how the technology would impact the FOMs but also why it would have that impact and for which architectures. These fields are directly controlled by the selections of Architecture Applicability at the top of the TDS. If "no" was clicked than these fields will be grayed out and locked, if "yes" was clicked than the fields will be opened for use. The impact ratings are a one digit value ranging from 1 to 5 as described by the scale on the left hand side of the section. The rationales noted should be specific to the particular architecture being evaluated. The Other 
Comments fields are the POC's chance to make note of any other pieces of information that the assessment or leadership teams should know about the technology and/or its development.
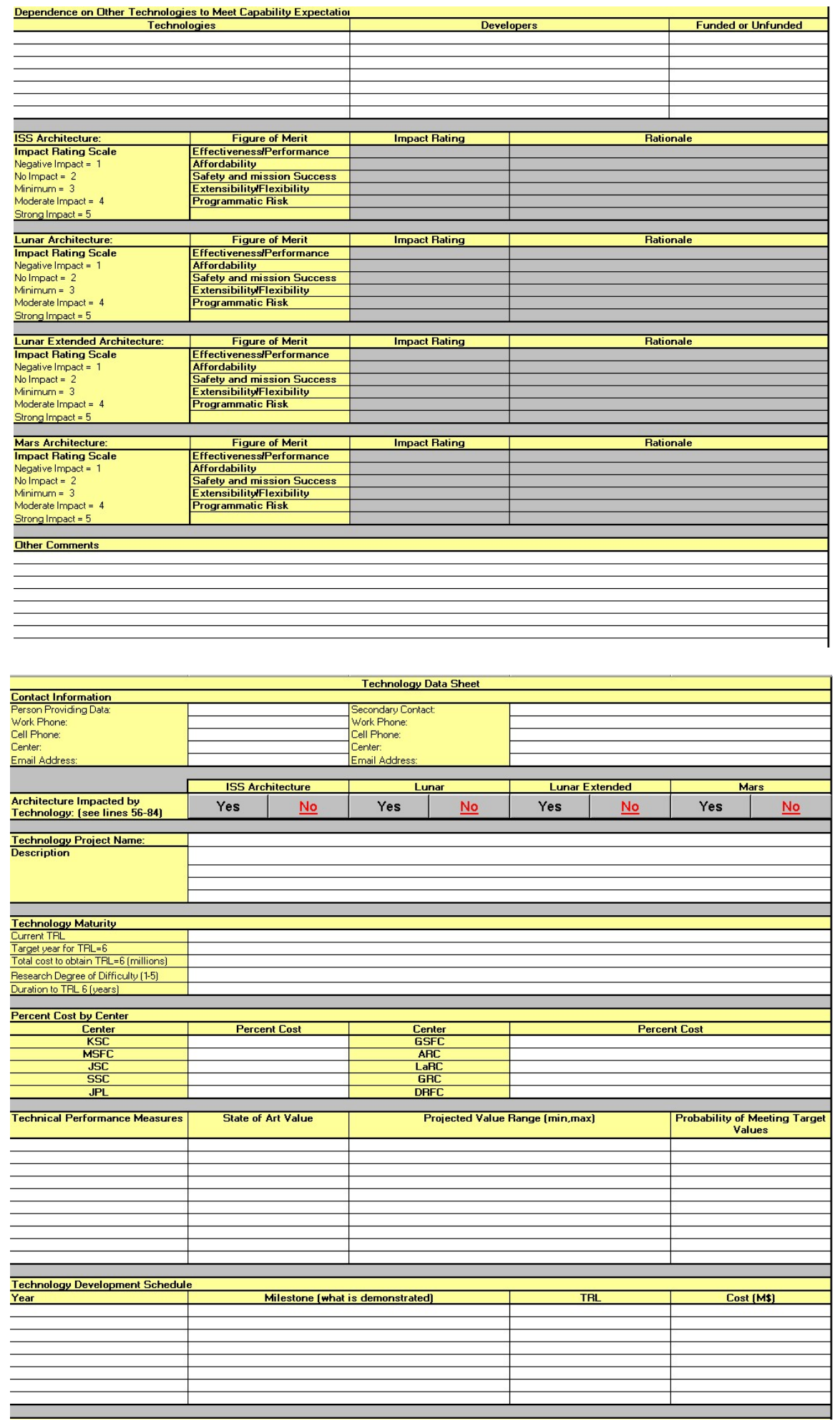

Figure 15. Technology Data Sheet 


\section{Existing Projects}

Also included as data input into the analysis process was that from the existing projects within the agency. Quad charts were gathered for each of the projects within the Human Systems Research \& Technology (HSR\&T), Exploration Systems Research \& Technology (ESR\&T), and Prometheus

development programs. Legacy projects were not included, as they were due to be terminated at the end of FY'05. The existing projects were treated nearly identical to the TDSs. Each was reviewed and assigned to applicable FBS areas, architectures, and elements with the aid of the NASA Langley POCs. A further detailed mapping of HSR\&T projects to the previously submitted TDSs was provided by the Implementation Team and EAP members that work on those TDSs. The vital information for the SC, and as much enhancing information as possible, was extracted from the quad charts and captured in an MS Excel file for inclusion in the SC along with similar data from the TDSs.

\section{F. Technology Prioritization Assessment Process}

A capability was provided to the ESAS team to rack and stack the necessary technology solutions to meet the three primary missions for the Space Exploration initiative and was called the Space Calculator. The foundation of the Space Calculator approach was based on the research conducted under the National Institute of Aerospace Grant number NCC-1-02043 entitled "Integration Plan for Future NASA Aircraft research Program". The robustness of the final tool delivered to the ESAS team allowed for the variation in annual budget, the specification of the TRL 6 date for each mission, and the flexibility to change the solutions, budget distributions, priorities, and durations. The results of the calculator execution would allow for traceability of the decisions made for the ESAS recommendations. By combining inputs from the Implementation Team and the Expert Assessment Panel, the final plan could be developed in a dynamic and iterative fashion. This information needed for the Space Calculator is illustrated in Figure 16.

Two primary tiers of information that were necessary to build the Calculator included:

- $\quad$ Relationship of the mission critical needs to the Figures of Merit (FOM)

- Relationship of the EAP technology solutions to the critical needs for each mission

The common theme between the two tiers was the definition of the mission architecture and the associated elements necessary to accomplish each mission's list of critical needs. The Architecture provided this taxonomy and element list of which was extensively utilized in the Calculator. At the top tier was the EAP Management Matrix mapped to the missions FOMs. The lower tier of information was referred to as the "Planning Matrix", which related the technology solutions identified from the EAP to the critical functional needs defined by the ESAS core team as structured by the Architecture team's taxonomy. 


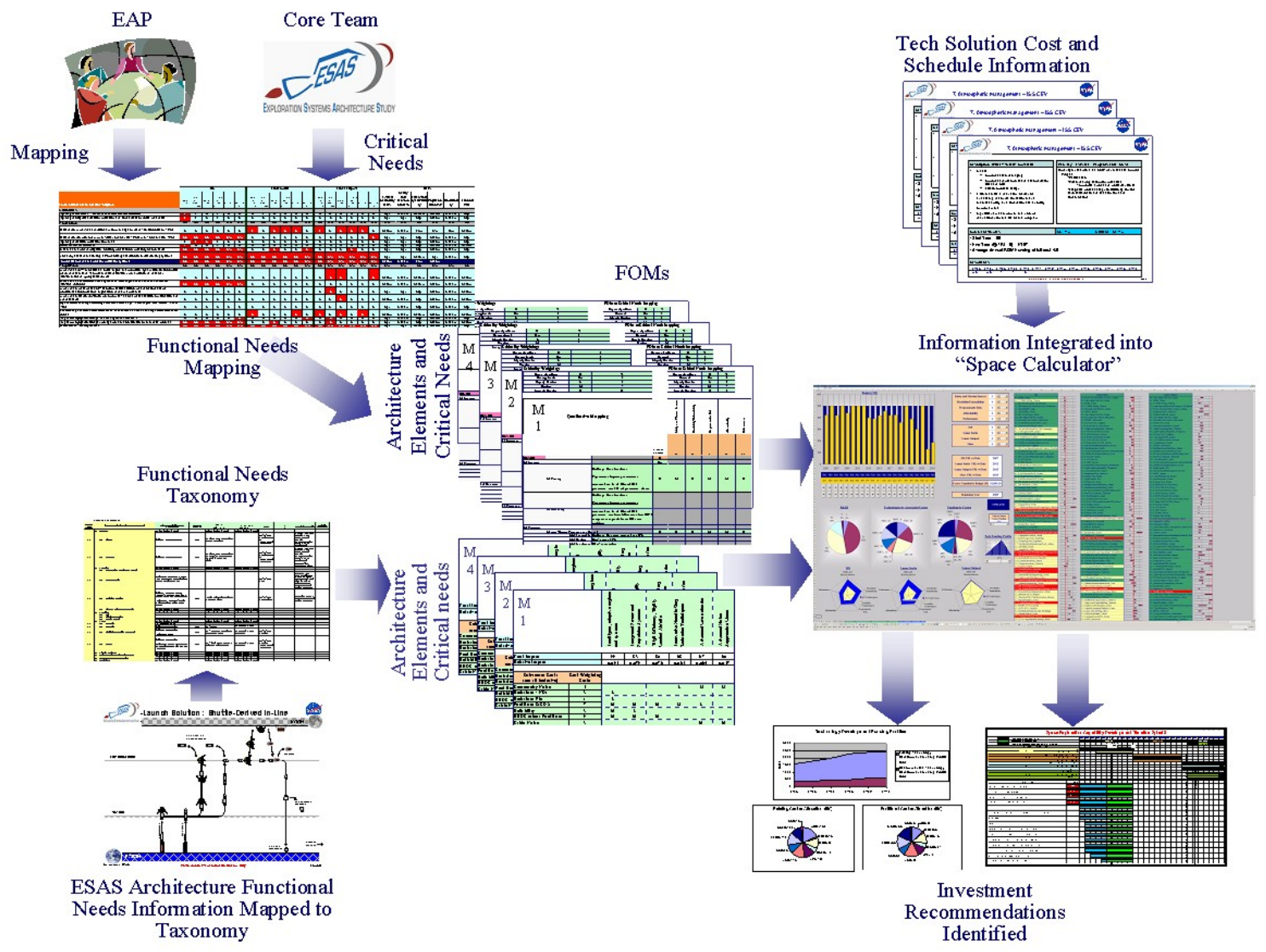

Figure 16. Information Flow of the Space Calculator

In the EAP Management Matrix, a qualitative mapping between the critical needs of the element FBS to the FOMs was established via a voting procedure during the final meeting. The qualitative mapping was then translated into a quantitative scale as defined by:

- $\quad$ High impact $=9$

- $\quad$ Medium impact $=7$

- $\quad$ Low impact $=1$

- $\quad$ Not applicable $=0$

- $\quad$ Negative $=-2$

Additionally, each of the FBS critical needs was classified in terms of criticality to each mission with the same qualitative definitions as above, but with a slight modification to the quantitative score where a high impact was defined as a value of 10. From the quantitative mappings, sensitivities of the mission elements could be determined.

In the Planning Matrix for the EAP solutions to the mission element critical needs, a similar qualitative mapping was conducted. However, the qualitative scale was modified to:

- $\quad$ Strongly exceeds need $=9$

- $\quad$ Exceeds need $=7$

- $\quad$ Meets need $=1$

- $\quad$ Not applicable $=0$

- $\quad$ Does not meet need $=-2$ 
By default, each of the solutions proposed by the EAP was assumed to meet the need. Hence, within the Planning Matrix, a solution was mapped to the appropriate element FBS for a given mission as listed below in Table 4.

For each EAP solution, the following reference information was obtained:

- $\quad$ TRL $=6$ date

- $\quad$ Total cost to reach TRL $=6$

- $\mathrm{RD} 3$

- Annual funding profile

- Mission applicability

Based on the two tiers of matrices and the information for each EAP solution, the foundation of the Space Calculator was established. Additional features were added for robustness, flexibility, and extensibility.

The main page of the calculator is where "what-if" games can be played, while the supporting tabs allow the user to make fundamental changes in the assumptions. The main page is divided into four primary regions: budget information, input weightings and required TRL $=6$ dates, the rack and stack of solutions and associated schedules, and the resulting portfolio impact on RD3 and center splits.

The budget profile allows the user to visualize the resources used by the funded technology solutions versus the maximum allowable funding. An allowable yearly budget profile is input, giving the Space Calculator's algorithm a limit to avoid exceeding when appropriating funds to technology solutions. Additionally, the funding used by "Gotta Have" technology solutions is shown to demonstrate the level of funding they require and also to allow for visualization of additional technology solutions that could possibly be funded. An adaptable generic technology funding profile was also provided on the main page, which shapes the required funding of a technology solution over its duration if a funding profile was not defined.

In the middle section of the Space Calculator, the user has the ability to change the relative importance amongst top-level FOMs, in addition to mission preferences, and individual element priorities for a given mission. Altering these values will reprioritize the technology solutions such that the chosen solutions to fund may change in addition to the schedules. Additionally, the user has the freedom to change the required TRL=6 date for each of the missions, which will alter the necessary funding and schedule profile.

To the right of the main page, for a given set of inputs and annual funding allotments, the Space Calculator will rack and stack the full set of EAP solutions, as broken into the four missions. The basis of the rack and stack is determined from the impact of the solution to the element FBS, the FOMs, and whether the solution is a "Gotta Have" or a "Wanna Have". When funding technology solutions, the calculator activates all "Gotta Haves" first. "Gotta Have” solutions begin being funded immediately after the previous mission's deadline if this allows for the solution to meet the current mission's TRL $=6$ date. If this is not possible, the solution is instead funded sufficiently early to meet the required deadline. Once all "Gotta Have" solutions have been funded, the calculator then begins funding "Wanna Have" solutions. Should the allowable budget be exceeded by only "Gotta Have" solutions, then the calculator assumes that one or more of the missions may be impossible to fund and suggests that the user inspects the various inputs. Otherwise, "Wanna Have" solutions are funded only if they can be funded continuously without the total budget exceeding the allowable budget input by the user. If the budget is completely used up or the calculator exhausts all given technology solutions, their respective information are then shown on the main calculator page, ranked by their "Gotta Have" status and their impact to the defined Figures of Merit. If a solution is funded and meets the required mission TRL $=6$ date, it is color coded as green. If a solution that was a "Gotta Have" for any of the missions is funded but not meeting a particular mission TRL = 6 data, it is color coded as yellow to prompt the user to investigate the schedule for the solution. If a solution is color coded as grey, it is not funded in that mission time frame.

To the lower left portion of the Space Calculator are the results of the annual funding and schedule assumptions. The RD3 of the funded solutions is shown in a pie chart. The number of active solutions proposed by each center is also shown. The right two pie charts demonstrate the percentage of funding going to a given center. The top right pie chart shows the funding breakdown for a specified year while the bottom right pie shows the total funding breakdown over the life of the program. Radar charts at the bottom of the page display the relative impact to the top level figures of merit for the funded technology solutions versus the total solution portfolio for each mission.

Finally, to make the calculator more robust, options were added to allow the user to override the calculator's decisions. An earliest start year could be input for any technology solution, which tells the 
calculator that a given solution may not be started until the specified year for reasons not otherwise accounted for in the input information. Additionally, a human override is allowed that will make the calculator begin funding a technology in a specific year, regardless of other inputs.

Table 4. Mapping Assumptions of EAP Solutions to Architecture Elements and FBS

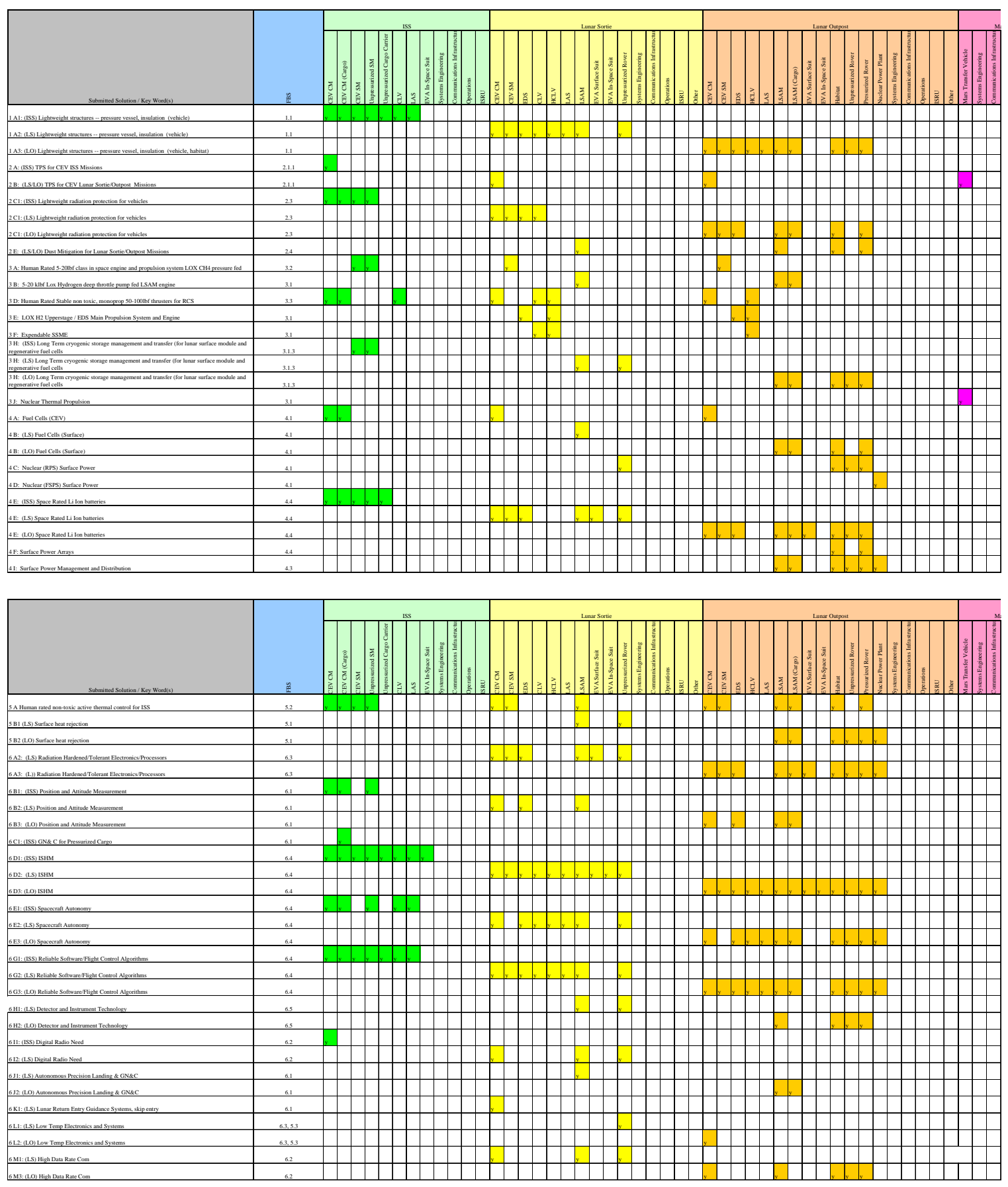


Table 4. Mapping Assumptions of EAP Solutions to Architecture Elements and FBS (cont.)
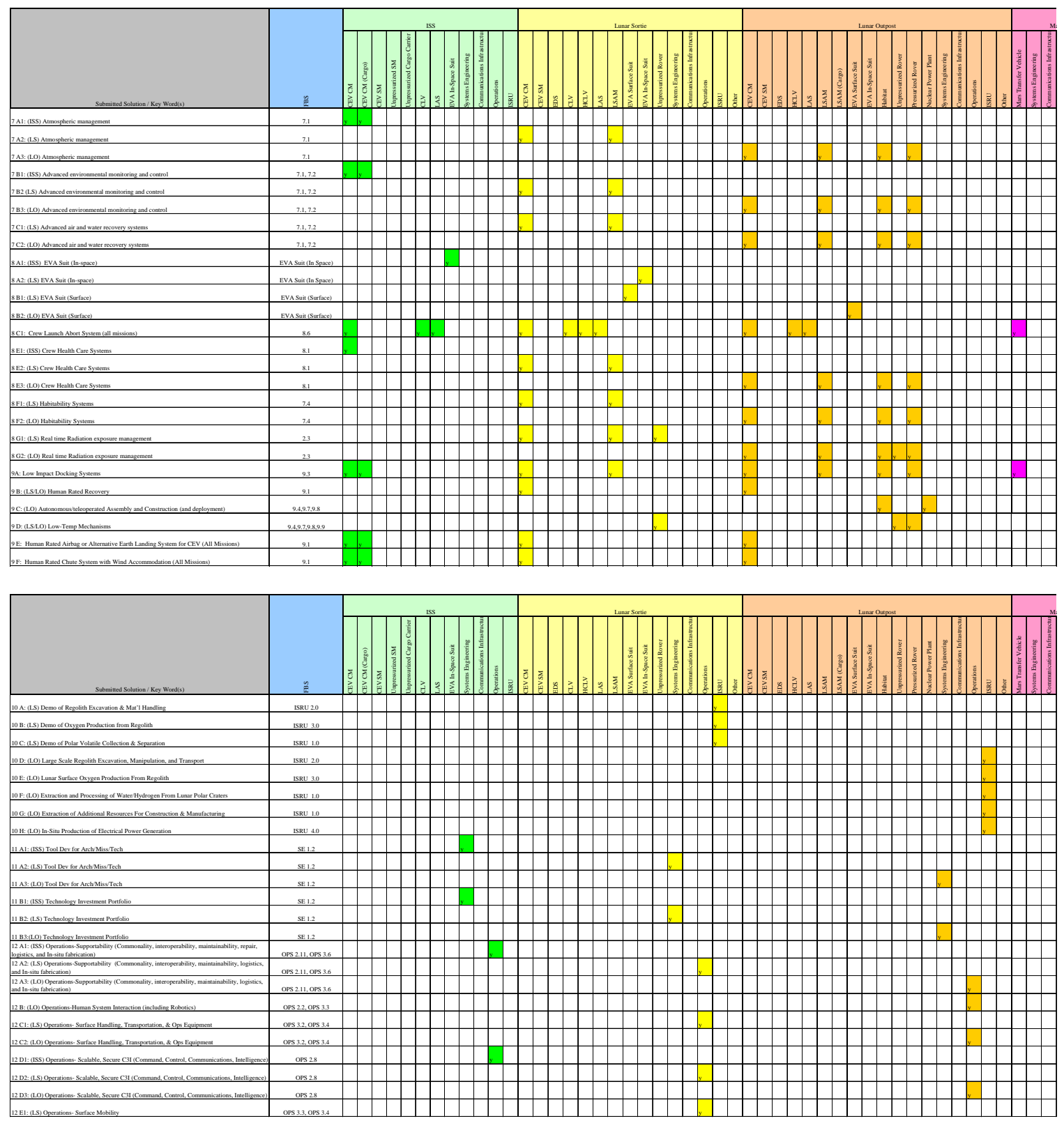

\section{Summary}

The exploration systems analysis capabilities applied and/or developed during the ESAS activity for strategic assessment, architecture development and technology assessment were identified as needed in support of a continued ESMD decision support system. The ESMD Directorate Integration Office (DIO) at NASA Headquarters established an on-going task to facilitate an "ESAS-like" strategic analysis capability to help in the establishment and continuous assessment of Level 1 requirements in support of the Vision for Space Exploration. The products of this task include alternative advanced exploration architectures, associated advanced concepts and technology performance needs, assessments of architecture sensitivities to requirements and technology changes using established Figures of Merit, technology assessments and 
strategic technology portfolios, and the integration of these assessments into effective information transfer mechanisms. This is a systems analysis activity that will repeat on an annual basis (see figure 17) as explorations systems are developed and refined in support of the Vision for Space Exploration. The driving factor for deliverables is the annual POP call in the spring. The cycle is driven by prioritized capability needs provided by HQ sponsored requirements definition studies and by the Level 2 program offices assessed against ongoing technology development efforts. The significant gaps and overlaps are then adjudicated leading to an integrated technology investment portfolio recommendation that feeds into the POP call. Inherent in this process is also a continuous improvement in the analytical capabilities supporting the decision making process.

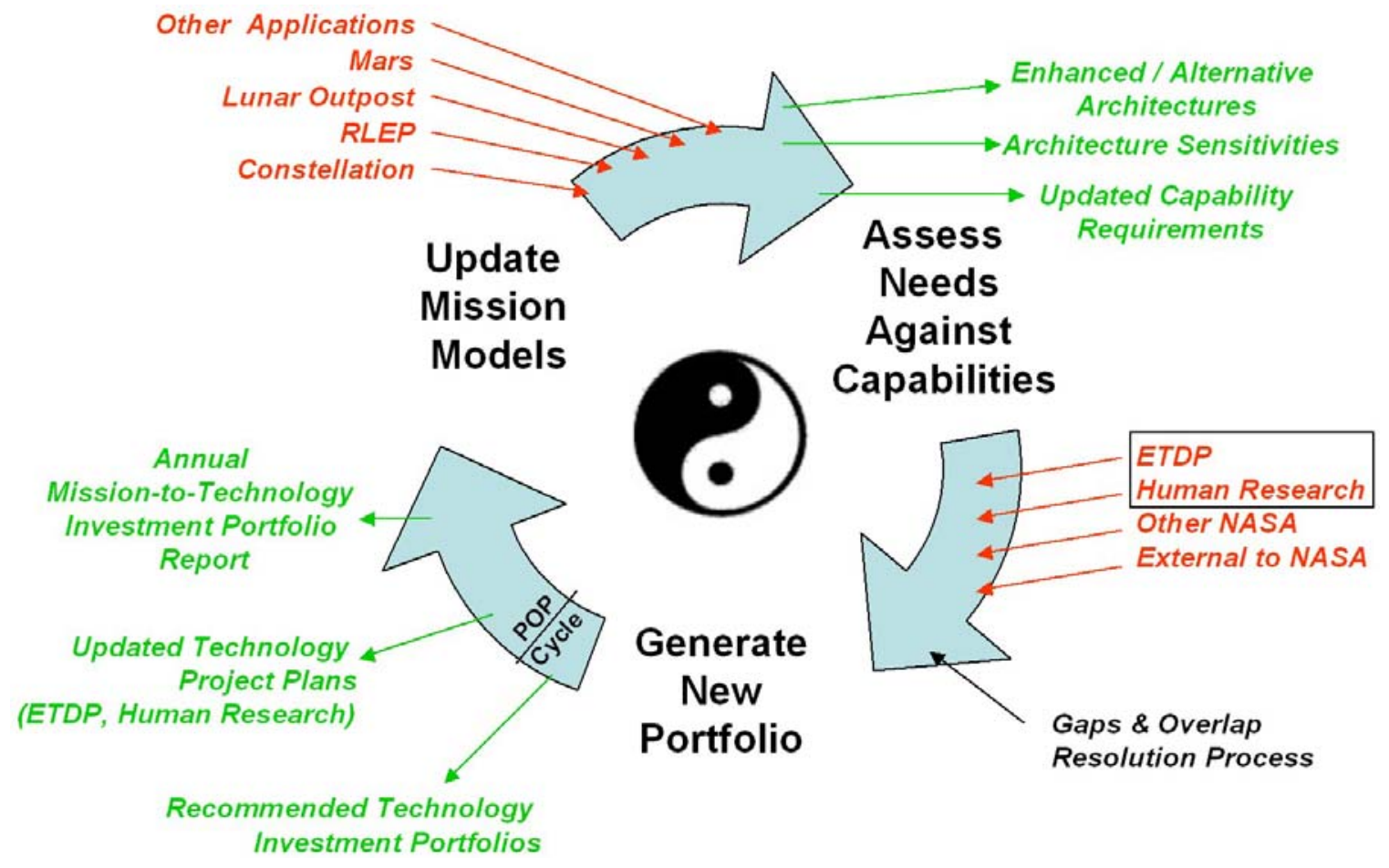

Figure 17. Annual Exploration Systems and Technology Assessment Cycle 